\title{
LA MUNTANYA ASSOLADA (ALZIRA, VALENCIA)
}

\author{
BERNARDO MARTI OLIVER \\ Servicio de Investigación Prehistórica. Valencia
}

\begin{abstract}
En el contexto de la Cultura del Bronce Valenciano el poblado de la Muntanya Assolada adquiere gran importancia por los restos constructivos exhumados hasta ahora, singularmente su muralla y el sistema de acceso al interior del recinto, así como por la riqueza de sus materiales arqueológicos. Las campañas de excavación realizadas, además de revelar la estructura general del poblado, han ofrecido una gran variedad de materiales que se apartan de la monotonía siempre aludida al hablar de esa Cultura. Destacan los análisis de los objetos metálicos, que nos demuestran la presencia de piezas hechas de bronce, así como el avance al estudio de los restos faunísticos, de los que se desprenden consideraciones sobre el medio ambiente y una imagen propia de una pequeña comunidad campesina.
\end{abstract}

Dans le contexte de la Culture du Bronze Valencien, le village de la Muntanya Assolada est très important pour les restes de construction mis à jour jusqu'à présent, particulièrement sa muraille et le système d'accès à l'intérieur de l'enceinte, ainsi que la richesse de son matériel archéologique. Les campagnes de fouilles effectuées, en plus de montrer la structure générale du village, ont apporté une grande variété de matériel qui s'éloigne de la monotonie dont on fait généralement allusion en parlant de cette Culture. Il faut souligner les analyses des objets métalliques, qui nous montrent la présence de pièces faites en bronze, ainsi qu'une approche de l'étude des restes de faune à partir desquels on peut aider à reconstruire le milieu ambiant et l'image d'une petite communauté paysanne.

\section{Situación}

Al S del río Xúquer y cerca de Alzira, con clara dirección NO-SE hacia el mar, se alza bruscamente sobre la Ribera un aislado eslabón final del Sistema Ibérico al que se donomina, por extensión, Serra de Corbera. Está formado por un anticlinal calcáreo jurásico-cretáceo profundamente carsificado y desventrado por la Vall d'Aigües Vives, con la Serra de les Barraques, de formas aplanadas al SO, y la Serra de les Agülles en áspera crestería al NE; en este flanco se adosa otro anticlinal fallado con la Serra del Cavall Bernat y la Vall de la Murta (LOPEZ, 1966, 391).

La Muntanya Assolada es uno de los espolones septentrionales de este conjunto montañoso, entre la Vall de la Murta y el Barranc de l'Aixavegó, dominando la llanura del Xúquer. Sus coordenadas son $30^{\circ} 08^{\prime} 40^{\prime \prime}$ de latitud N y $3^{\circ} 18^{\prime} 15^{\prime \prime}$ de longitud E del meridiano de Madrid. El yacimiento prehistórico se encuentra en su pequeña cumbre amesetada, alcanzando una altura de 227 metros sobre el nivel del mar (fig. 1).

El topónimo Muntanya Assolada requiere de un pequeño comentario porque, si bien a la vista de los resultados de las campañas de excavación podría pensarse en la lejana evocación de un asentamiento humano arrasado con el paso del tiempo, lo cierto es que el calificativo de assolada responde al parcial hundimiento de la montaña y zonas 


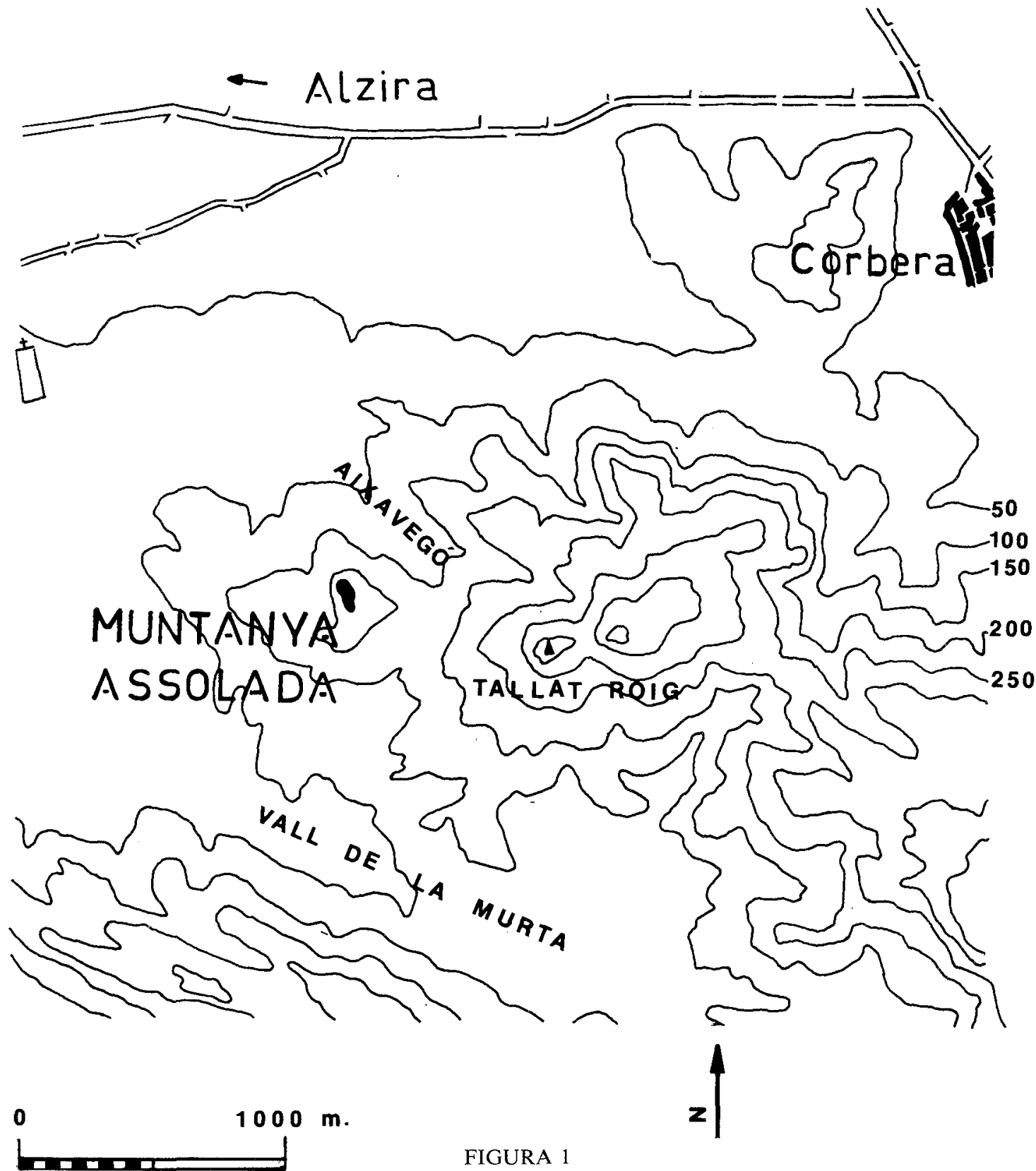

adyacentes acaecido en el otoño de 1783. Hasta entonces el lugar era conocido como Muntanya de la Font de Baladre (A.M.A.; SAN PEDRO, 1784; CAVANILLES, 1795, 209; PELUFO, 1935). Este desmoronamiento no afectó a la cumbre donde se asienta el poblado aunque, en el transcurso de la excavación, pudieron observarse sus efectos, apareciendo una estrecha grieta en el suelo de la montaña, bajo potentes niveles de habitación, que según todos los indicios era posterior a la ocupación prehistórica de la cumbre.

En las proximidades de la Muntanya Assolada se conocen diversos yacimientos prehistóricos, atribuibles también a la Edad del Bronce o a los momentos finales del Eneolítico: la Muntanya de Carles, el Castell y el Puntal de l'Abuela en Corbera; el 
Cabeçol de l'Anell, la Cova del Barranc de Xarta y la Cova del Pic en Carcaixent; la Muntanyeta dels Galls y la Cova dels Gats en Alzira, etc.; yacimientos que en conjunto atestiguan un poblamiento notable para estos momentos.

\section{Las campañas de excavación: Los restos constructivos}

Las primeras noticias sobre la existencia de un poblado de la Edad del Bronce en la Muntanya Assolada se remontan a los años 1940-1941, en que por vez primera fue explorado por el P. Panach. En 1953 sería nuevamente prospectado por Gual y San Valero, quienes realizaron algunas catas en el altozano que «dieron por resultado el hallazgo de fragmentos de cerámica sin decoración, junto a restos de animales, conchas y moluscos y un pedazo de molino de piedra. Al pie del montículo se exploró un covacho en el que aparecieron más restos cerámicos y huesos humanos, lo que es indicio de su aprovechamiento como lugar de enterramiento» (GUAL, 1953).

Desde entonces no había sido objeto de atención y la observación superficial no hacía presagiar la potencia de su sedimentación y los restos constructivos, hasta que las obras para la urbanización de la zona pusieron de manifiesto la importancia real del asentamiento prehistórico. Iniciadas como trabajo de salvamento, las campañas de excavación comenzaron durante el verano de 1978, por parte del Servicio de Investigación Prehistórica de la Diputación de Valencia, con la oportuna autorización de la Subdirección General de Arqueología, continuándose en la actualidad.

La campaña de 1978 fue dirigida por D. Fletcher y B. Martí, continuándose por este último en los años siguientes junto a un equipo interdisciplinar formado por R. Enguix, P. Fumanal, M. Dupré, I. Sarrión, E. Torres y V. Lerma, que comprende los estudios sedimentológicos y polínicos, la determinación de los restos de fauna, los análisis de los objetos metálicos, etc., algunos de ellos en avanzado estado de elaboración. De especial importancia para estos trabajos ha sido la colaboración prestada por el propietario de los terrenos, J. Balaguer, y por el Ayuntamiento de Alzira, así como la ayuda de J. Matoses, A. Ferrer, A. Perepérez, M. J. de Pedro y otros vecinos de Alzira.

Con el importante condicionamiento de los trabajos de urbanización realizados, apertura de un camino en la parte occidental y desfonde parcial de la parte meridional de la cumbre, la excavación se centró inicialmente en las zonas afectadas, en las que los cortes estratigráficos parecían indicar la existencia de distintos niveles de habitación; pero, dadas las pequeñas dimensiones que son propias de los poblados de la Edad del Bronce en nuestras tierras, el objetivo prioritario de las campañas siguientes ha sido la excavación en extensión, buscando la delimitación exacta del poblado y la naturaleza de sus restos constructivos.

A lo largo de las campañas realizadas se ha exhumado una parte considerable de las estructuras del poblado, lo que permite esbozar ya sus características principales (fig. 2). Sobre la pequeña cumbre amesetada de la montaña, alargada en dirección NO$\mathrm{SE}$, el poblado tiene una planta aproximadamente rectangular de 40 por 20 metros de extensión. En su parte oriental el límite del asentamiento viene determinado por una abrupta pendiente, mientras en su parte occidental, así como en sus extremos norte y sur, se construyó una sólida muralla formada por sucesivas hiladas de piedras sin carear. En la misma parte occidental y por su cara externa, la muralla conserva el arranque de dos muros perpendiculares a la misma, que pronto se confunden con sus propios derrumbes, sin que resulte posible determinar precisamente el tramo final. Confusión a la que contribuyen la acusada pendiente sobre la que discurren estos muros, así como la existencia de abancalamientos realizados en los últimos siglos para la explotación de algarrobos y olivos. 


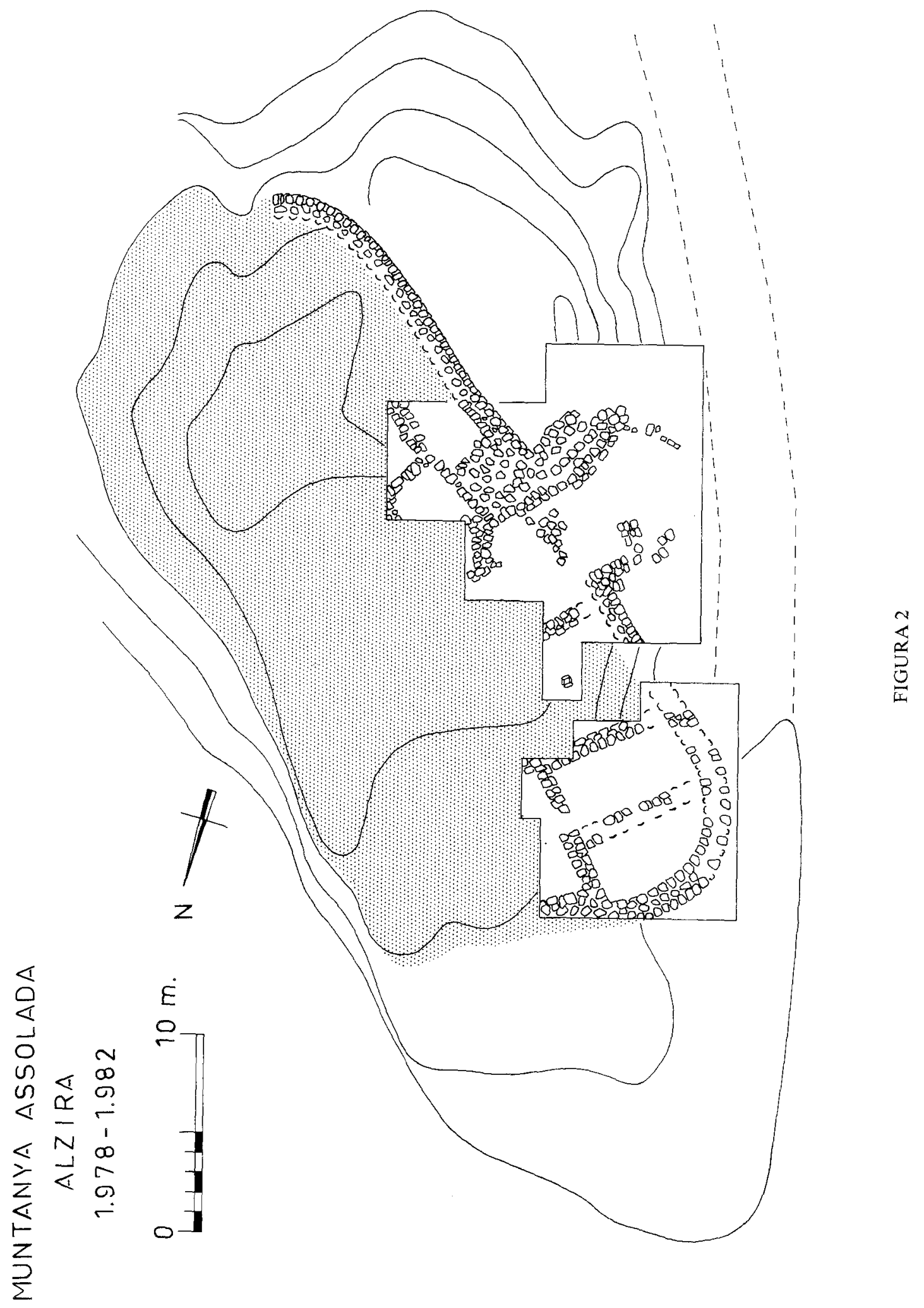


Como puede suponerse, determinar la naturaleza exacta de esta construcción adquiere gran importancia desde el punto de vista urbanístico, dada la posibilidad de que estemos frente al sistema de acceso al interior del poblado, o bien ante una construcción de tipo defensivo que sobresale de la línea de la muralla, o bien ante cualquiera otra posibilidad no contemplada hasta ahora. Aunque es prematuro descender a hipótesis concretas y esperamos que la zona interior del poblado aportará información complementaria al respecto, la hipótesis de que se trate del sistema de acceso al interior del recinto nos parece la más probable en estos momentos. La entrada se abriría en dirección NO, paralela a la muralla, para después formar un ángulo recto y, ya con dirección NE, perpendicular a la muralla, dirigirse al interior del poblado.

En el interior del recinto, los departamentos identificados son de planta rectangular, formados por muros de piedra hasta una altura no determinada. Se ha comprobado en un caso la existencia de un pavimento constituido por cantos irregulares de pequeño tamaño, así como una estructura de lajas de piedras verticales sobre otra horizontal, interpretada como la base de un poste para la sustentación de la techumbre. La presencia de fragmentos de barro con improntas de cañas y ramajes nos informa acerca de la naturaleza de estas techumbres y quizás de la parte superior de los muros de las casas.

Por lo que se refiere a la secuencia estratigráfica, el hecho de que los trabajos de excavación estuvieran inmediatamente condicionados por las obras de urbanización del yacimiento tiene gran importancia a la hora de examinar los resultados alcanzados. Hasta el momento sólo se ha evidenciado un nivel de estructuras de habitación, aunque la observación de los cortes abiertos indica al menos dos niveles de intensa ocupación. Pero sólo a partir de 1981 se ha podido acometer la excavación de la parte mejor conservada del poblado y, en consecuencia, resulta prematuro pronunciarse sobre ello. En cualquier caso sí puede afirmarse que el yacimiento tuvo una prolongada ocupación dentro de la Edad del Bronce, como se desprende del examen de los materiales recuperados.

\section{Los materiales.}

Las características generales de la cerámica confirman lo expuesto en numerosas ocasiones para el Bronce Valenciano: pastas poco depuradas que ofrecen un desgrasante abundante y de tamaño apreciable; las superficies de los vasos han sido predominantemente alisadas y, en mucha menor proporción, bruñidas. Las coloraciones de pastas y superficies varían de los tonos claros a los grises oscuros, en ocasiones sobre un mismo vaso. Con escasas excepciones no ofrecen decoración y los elementos de prehensión, asas y mamelones, también aparecen en pequeño número. Las formas mejor representadas son los cuencos de casquete esférico y semiesférico, los cuencos planos de casquete esférico o escudillas, los grandes cuencos o cazuelas de perfil semiesférico, los vasos carenados, los vasos globulares y ollas, los grandes recipientes u orzas, los vasos geminados y un número apreciable de bases planas sin forma precisa (figs. 3-10).

Cuencos y cazuelas son especialmente abundantes. En algún caso han sido decorados con series de pequeños mamelones junto al labio (fig. $3, n .^{\circ} 2$ ) o poseen un mamelón como elemento de prehensión en la mitad superior del vaso. Mención especial merece un cuenco semiesférico con buen tratamiento de las superficies y decoración incisa en su interior (fig. $8, \mathrm{n}^{\circ}{ }^{\mathrm{1}}$ ), y otro ejemplar de forma más abierta decorado con líneas incisas y pequeñas punzadas (fig. $8, \mathrm{n}^{\circ}{ }^{\circ} 6$ ).

Los vasos carenados muestran variaciones significativas en sus formas. Existen ejemplares de cuerpo globular con carena a media altura y cuello estrecho (fig. $6, n .{ }^{\circ} 1$ ), pero también encontramos vasos con carena en su mitad inferior y amplia boca que sobrepasa el diámetro de la carena (fig. 10). En este punto hemos de atribuir gran impor- 

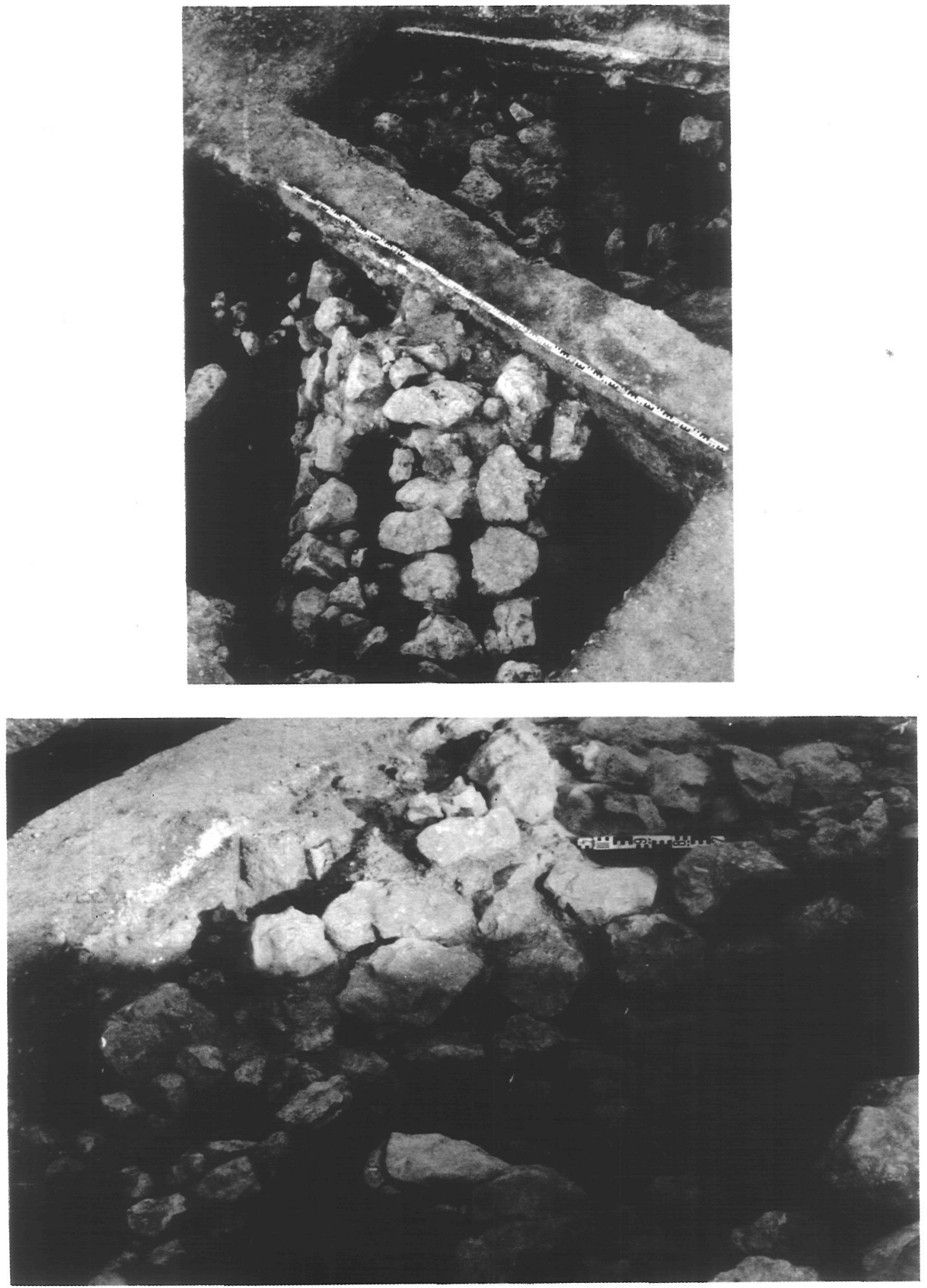

Muntanya Assolada. Muralla del poblado. 

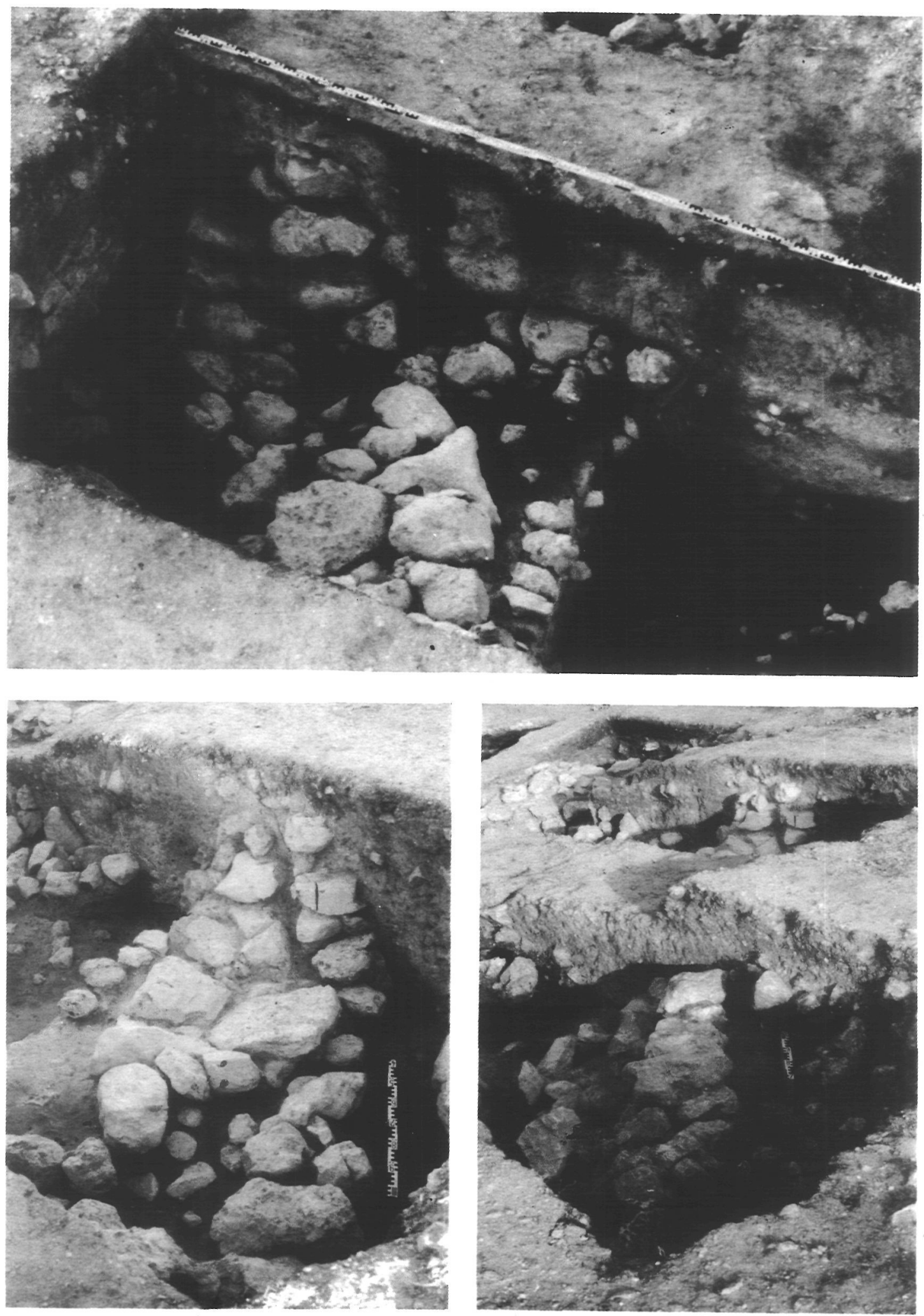

Muntanya Assolada. Muros de las habitaciones. 

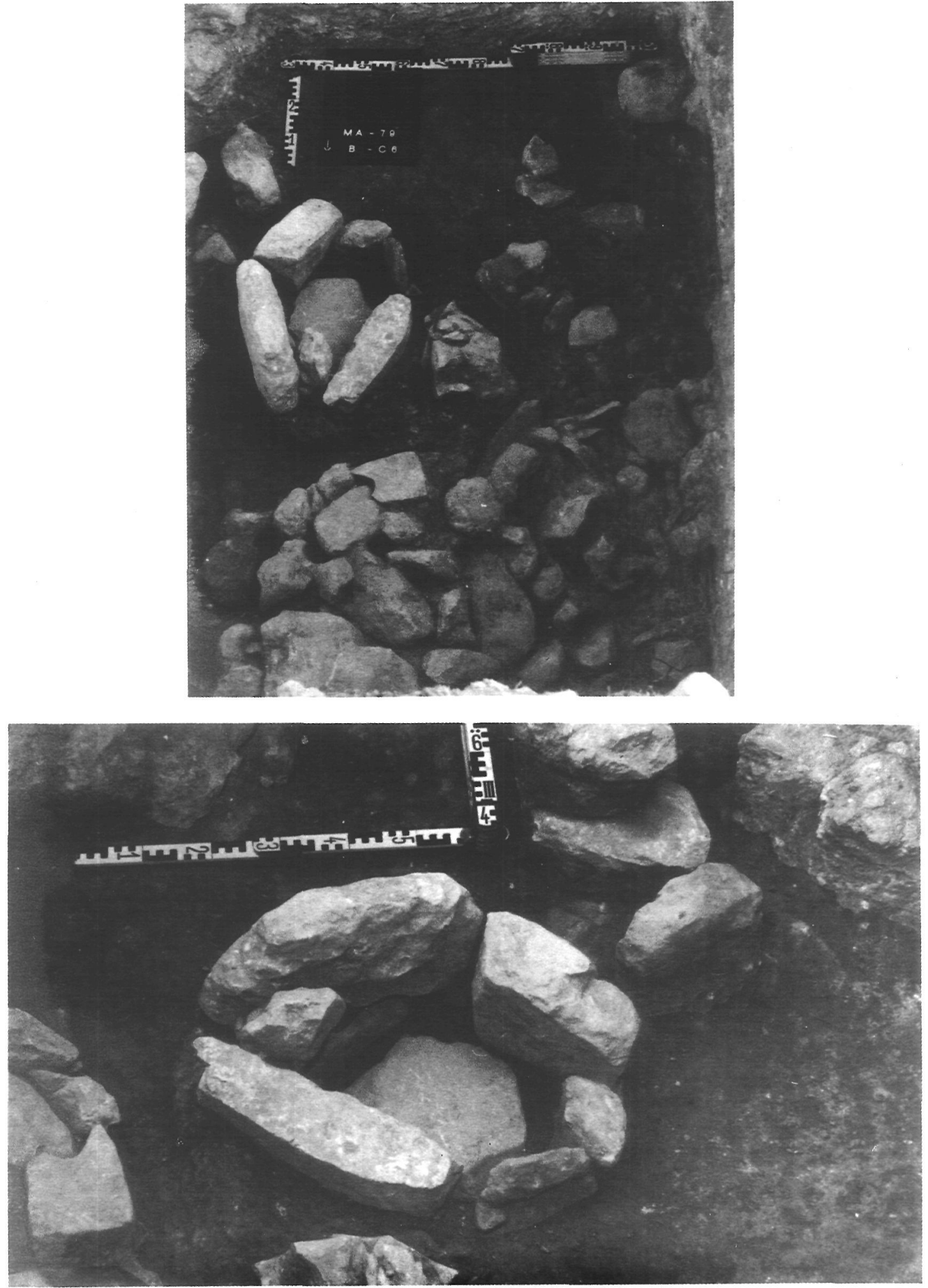

Muntanya Assolada. Estructura de piedras para la base de un poste. 

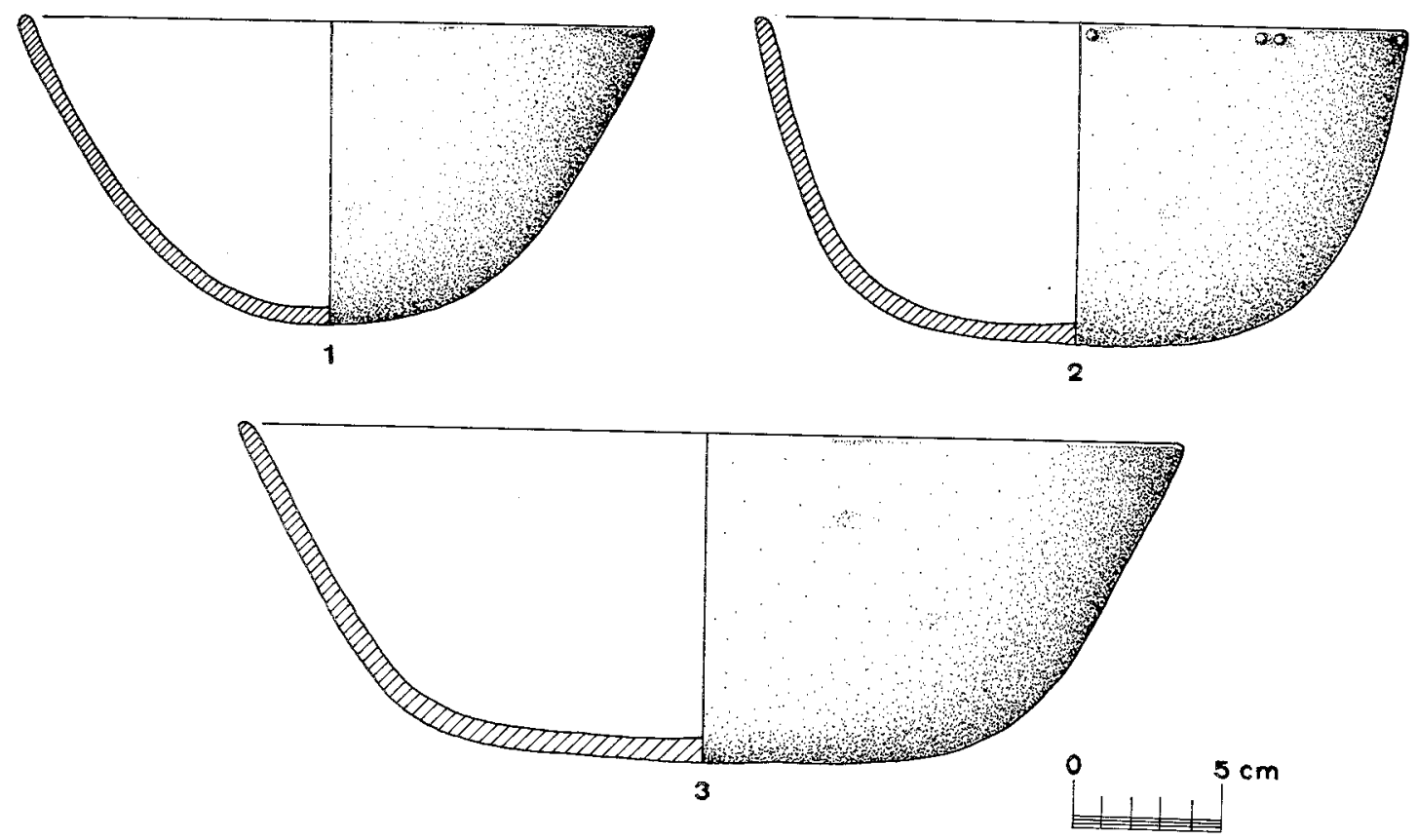

FIGURA 3

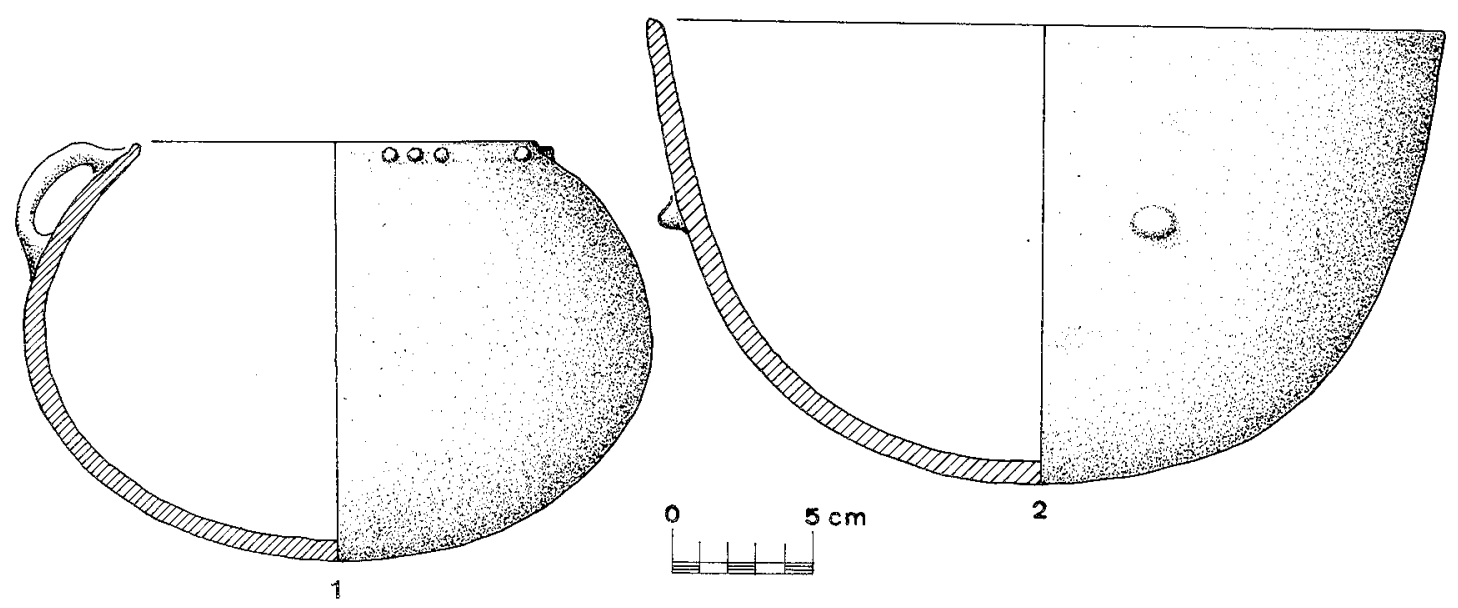

FIGURA 4 

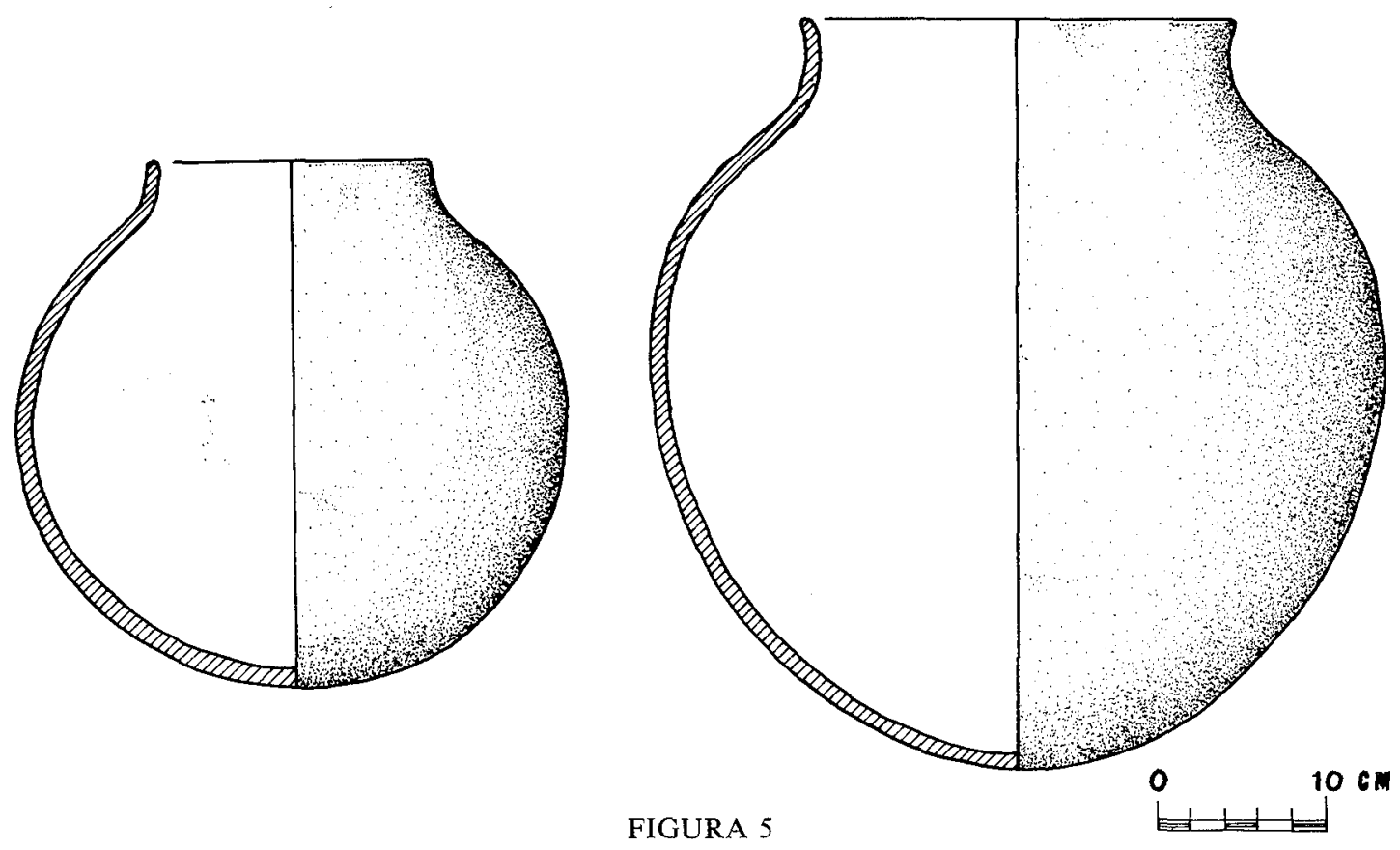

tancia al hecho de que las carenas bien marcadas y el mayor diámetro de las bocas parezca corresponder a las capas superiores del poblado, según los resultados de las últimas campañas de excavación.

Las ollas poseen perfiles variados aunque predominen las de paredes entrantes y borde ligeramente vuelto. Pueden llevar mamelones como elementos de prehensión o asas de cinta verticales. Destaca por su rica decoración de amplias incisiones un ejemplar con dos asas verticales simétricas en la parte superior (fig. 9). Entre las ollas de mayor tamaño o pequeñas orzas encontramos ejemplares de cuerpo globular con cuello recto ligeramente entrante (fig. $5, \mathrm{n} .^{\circ} 1$ ). Las orzas de mayor tamaño presentan cuello y labio ligeramente saliente (fig. $5, \mathrm{n}^{\circ} 2$ ).

Sin detenernos en las. restantes formas menos representadas, y en algunas otras muestras de decoración como las incisiones transversales en los labios o los cordones, destacaremos un fragmento de cuerpo de gran espesor con una decoración bruñida irregular que parece formar motivos triangulares alargados (fig. $7, \mathrm{n} .^{\circ} 2$ ).

La industria del sílex muestra la abundancia característica de los dientes de hoz, habiéndose recuperado también tres puntas de flecha, una de ellas de base cóncava, un trapecio asimétrico, algunos fragmentos de hojas y restos de talla (fig. 11).

Son escasas las hachas y azuelas de piedra pulida (fig. $11, \mathrm{n} \cdot{ }^{\circ} 12$ ), al igual que sólo conocemos dos brazaletes de arquero (fig. $11, \mathrm{n} .{ }^{\circ}$ 14) y una maza o martillo (fig. 12). Abundan, sin embargo, los percutores y las piedras de molino.

En la industria ósea existen punzones, generalmente de punta biselada, robustas espátulas a modo de cinceles, botones prismáticos triangulares con perforación en $\mathrm{V}$ (fig. 13), cuentas de collar discoidales (fig. 11, números 5 y 6), una punta de flecha y un posible fragmento de anillo con líneas incisas (fig. 13, n. ${ }^{\circ} 7$ ).

Algunos otros elementos de adorno como dos fragmentos de brazalete de piedra (fig. 11, números 10 y 13), numerosas conchas de Achantocardia tuberculata o Cerastoderma edule con el ápice perforado, etc., forman parte también de la cultura material de la Muntanya Assolada. 

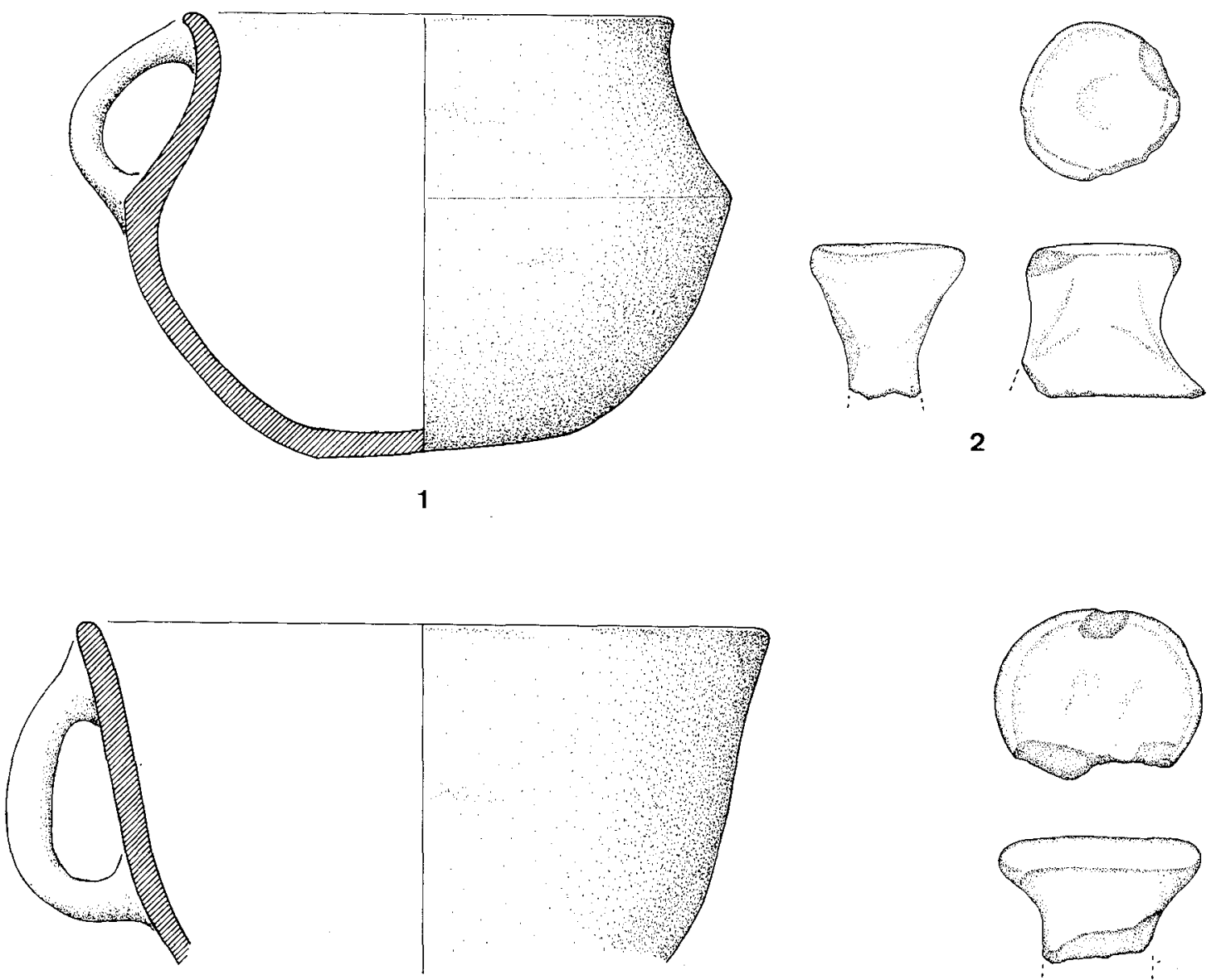

3
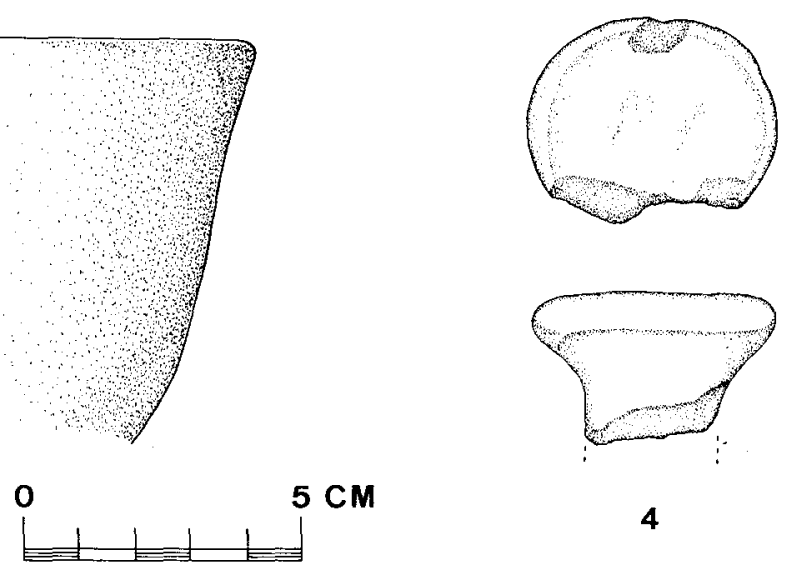

$5 \mathrm{CM}$

4

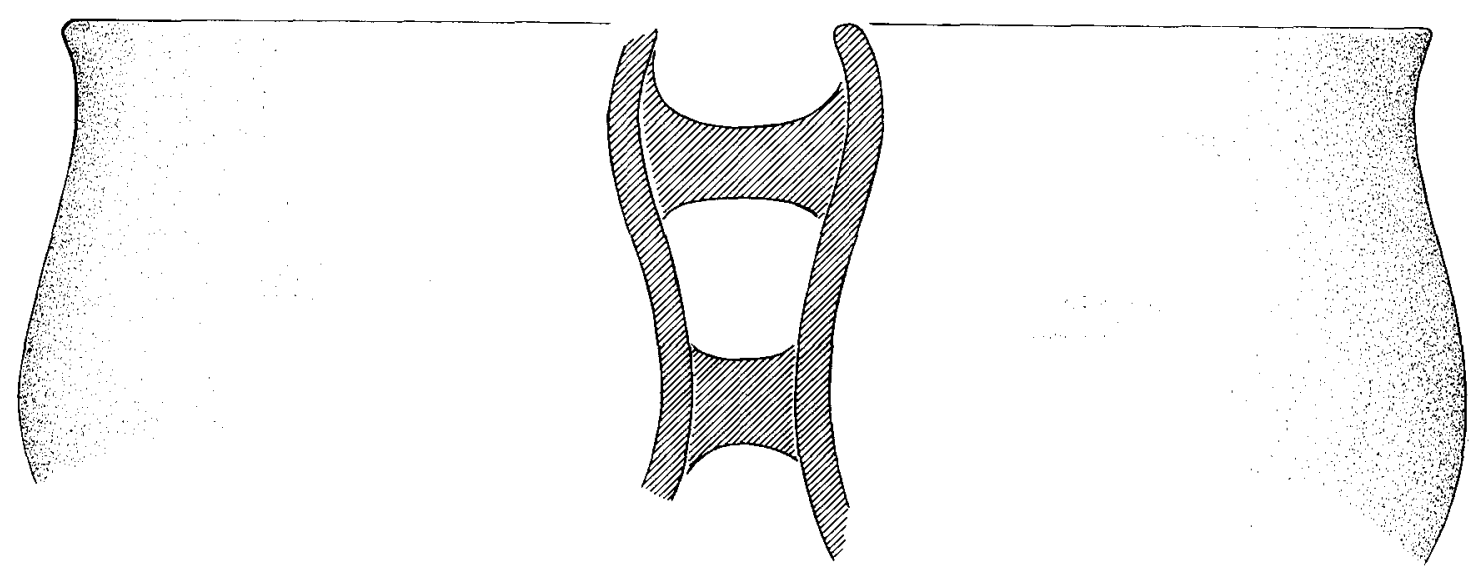

5

FIGURA 6 

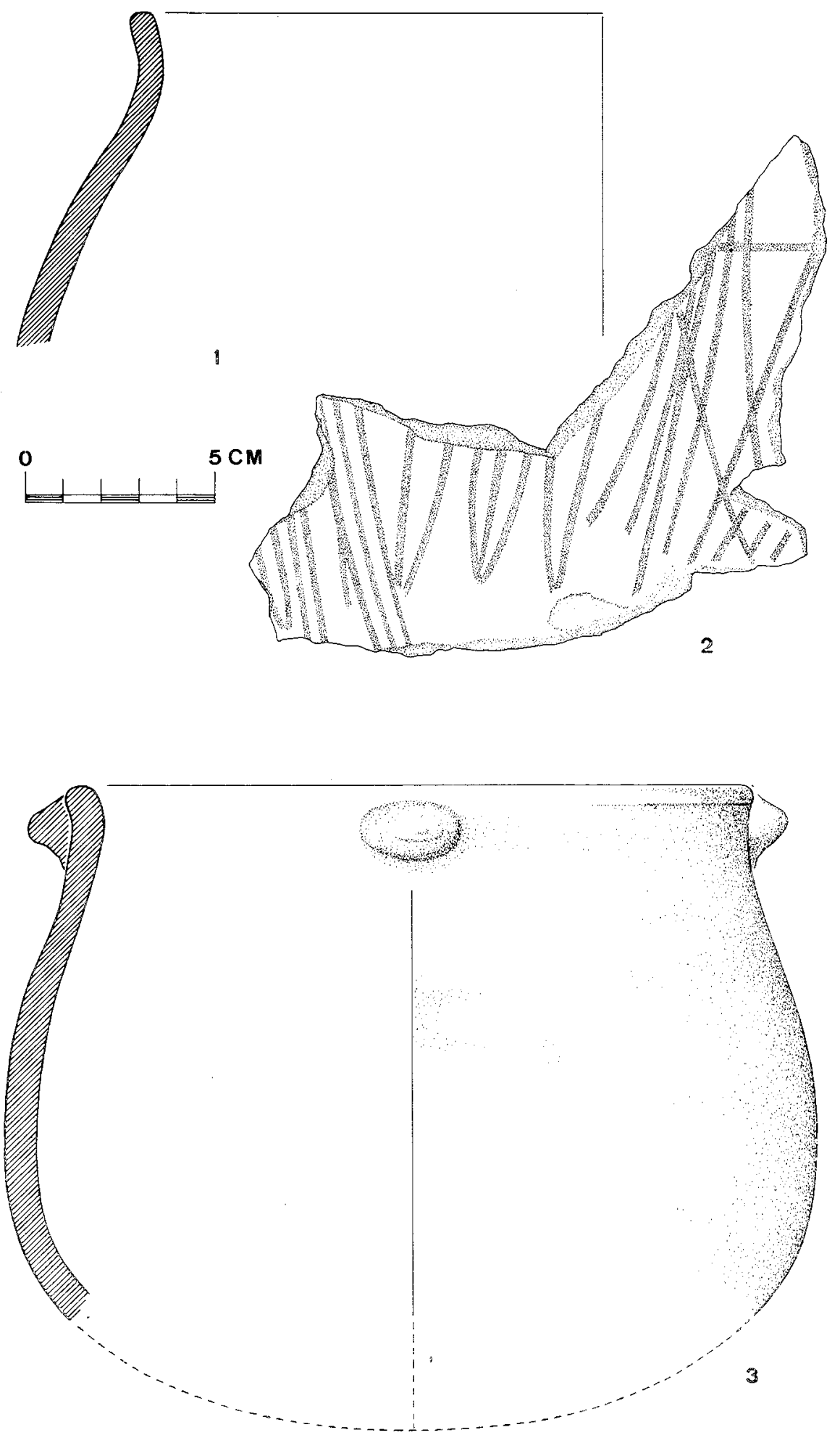

FIGURA 7 

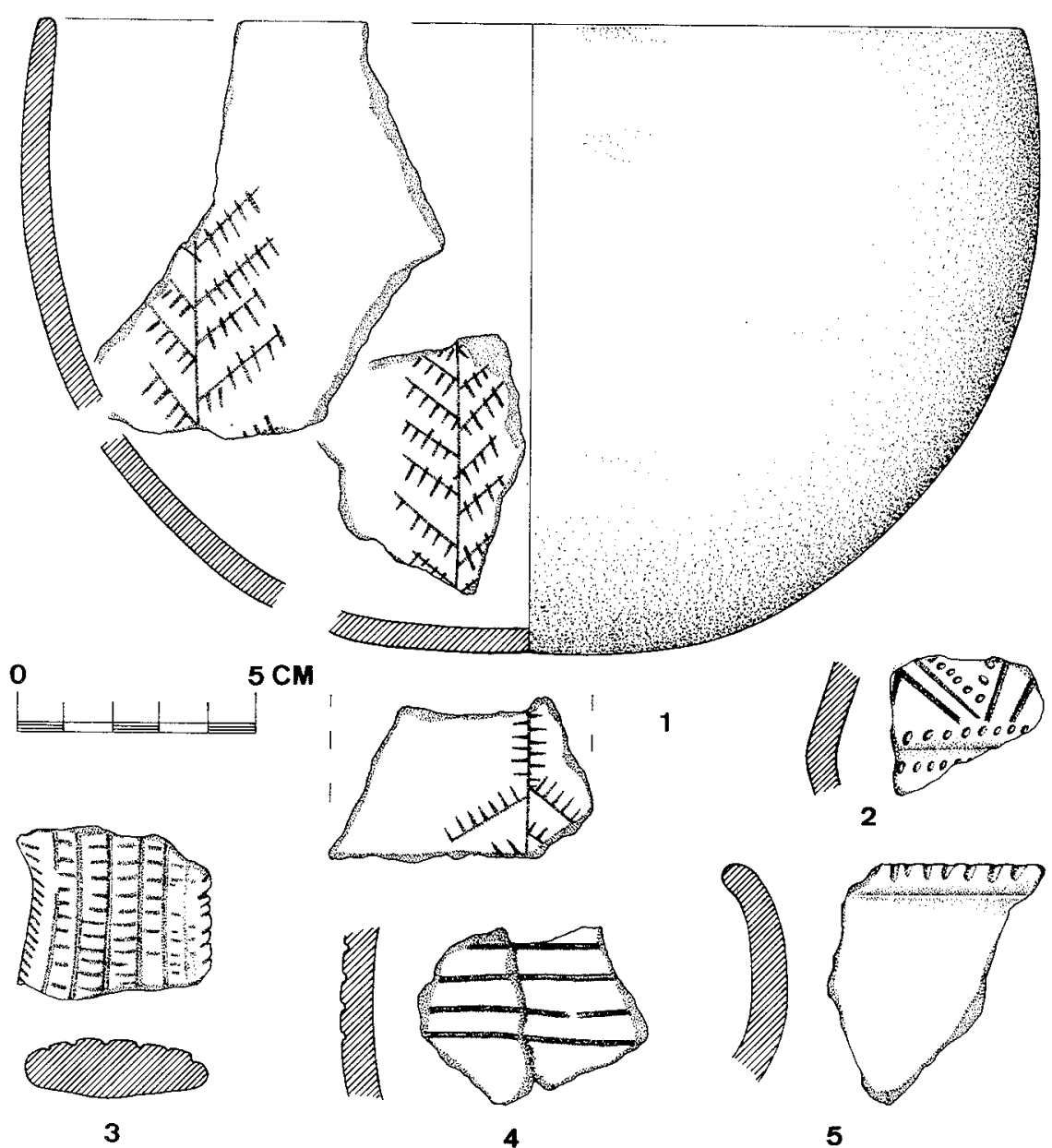

4

5

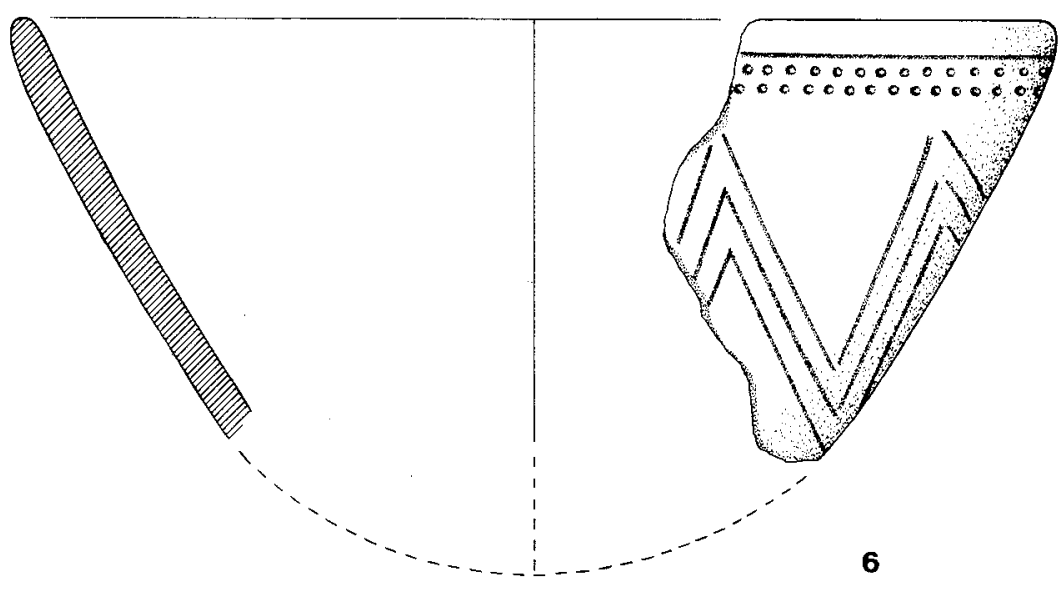

FIGURA 8 


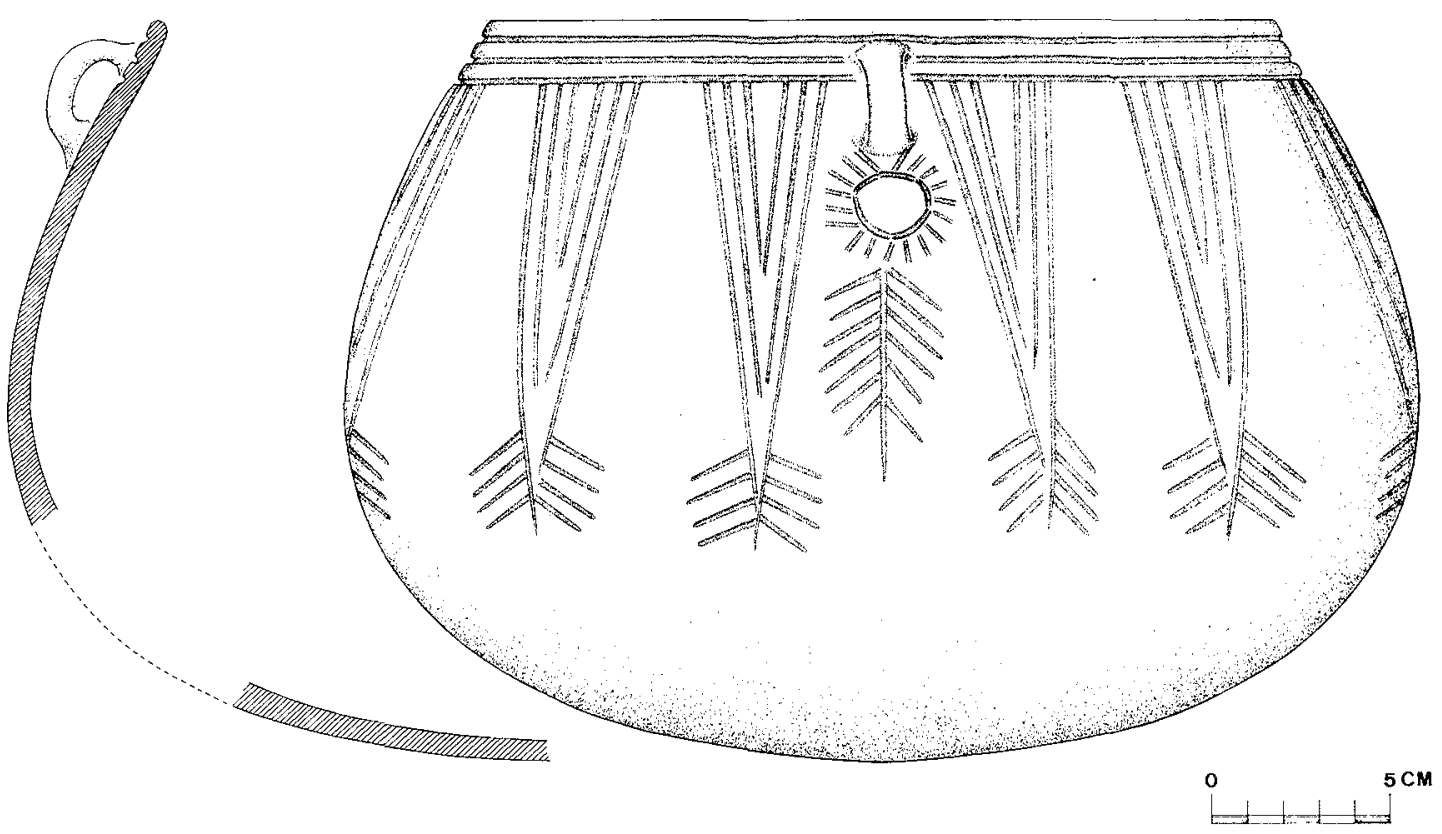

FIGURA 9

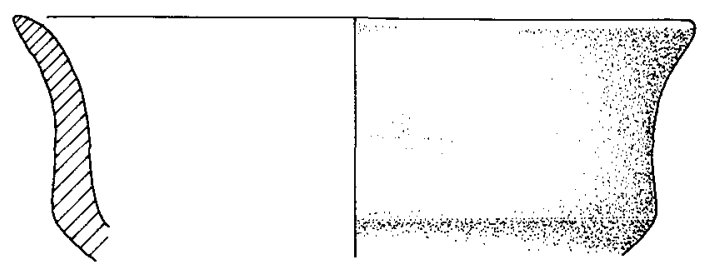

1
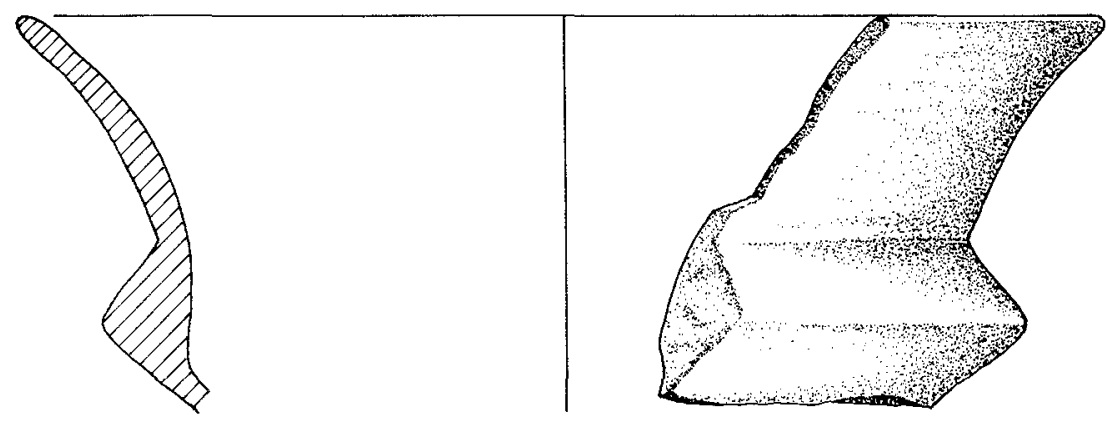

2

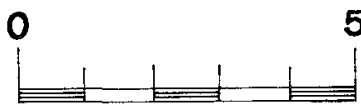

FIGURA 10 


$$
\begin{aligned}
& \$ D \\
& \perp \quad B
\end{aligned}
$$




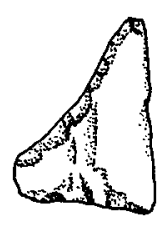

1

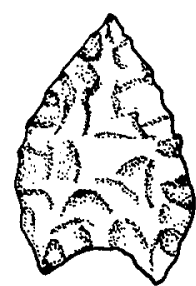

2

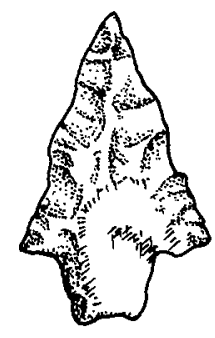

3

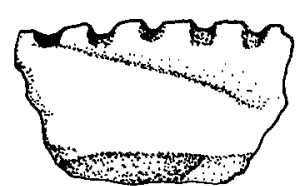

4

9

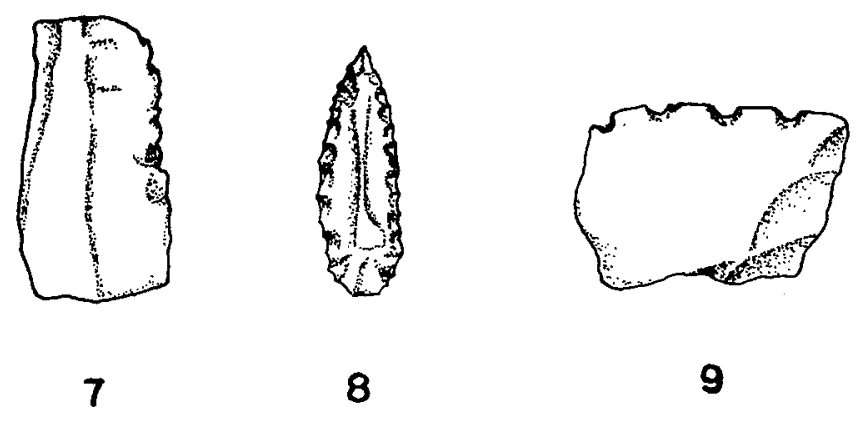

8
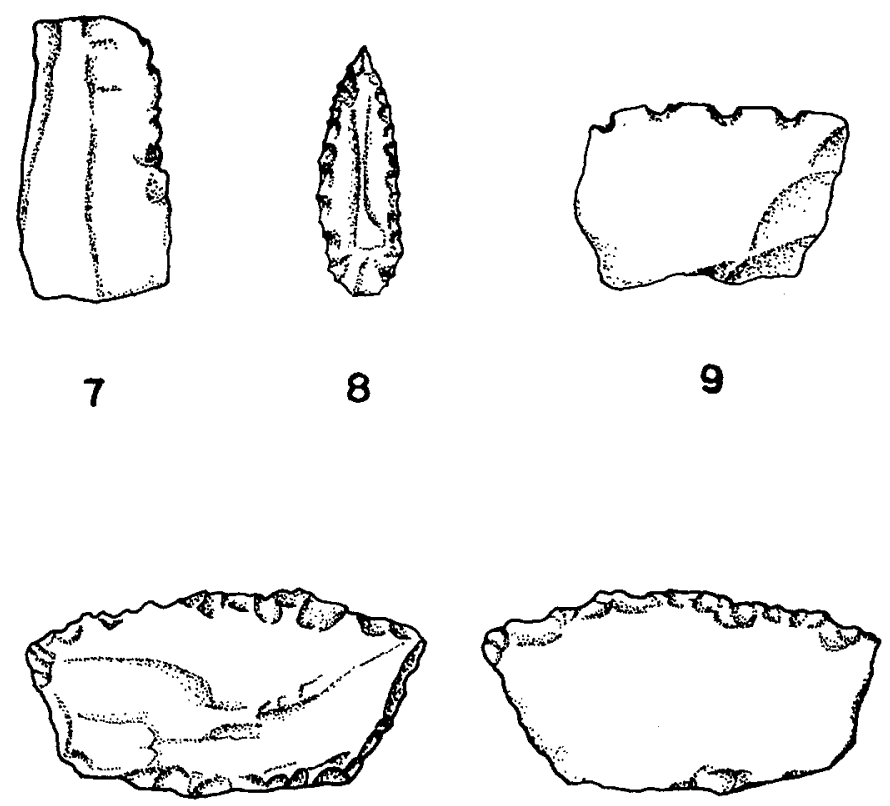

11
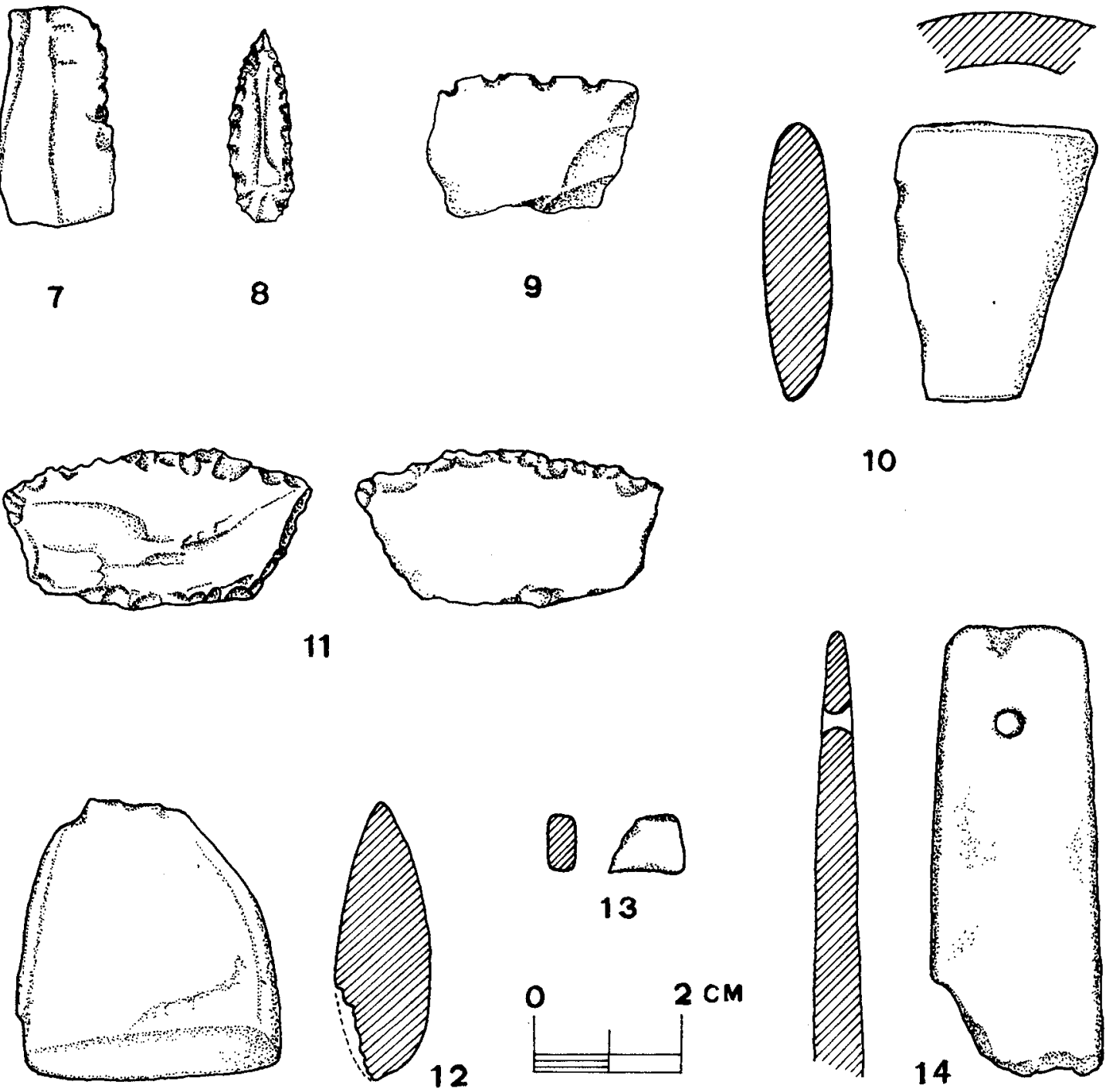

10

()

एक्षा

5

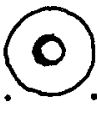

6

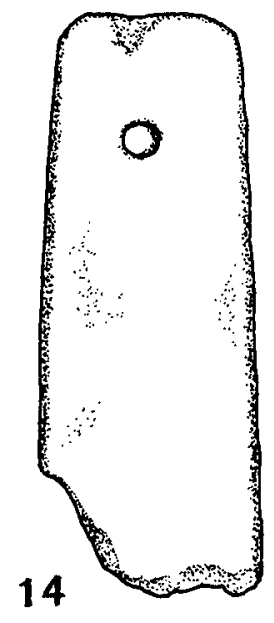

FIGURA 11 

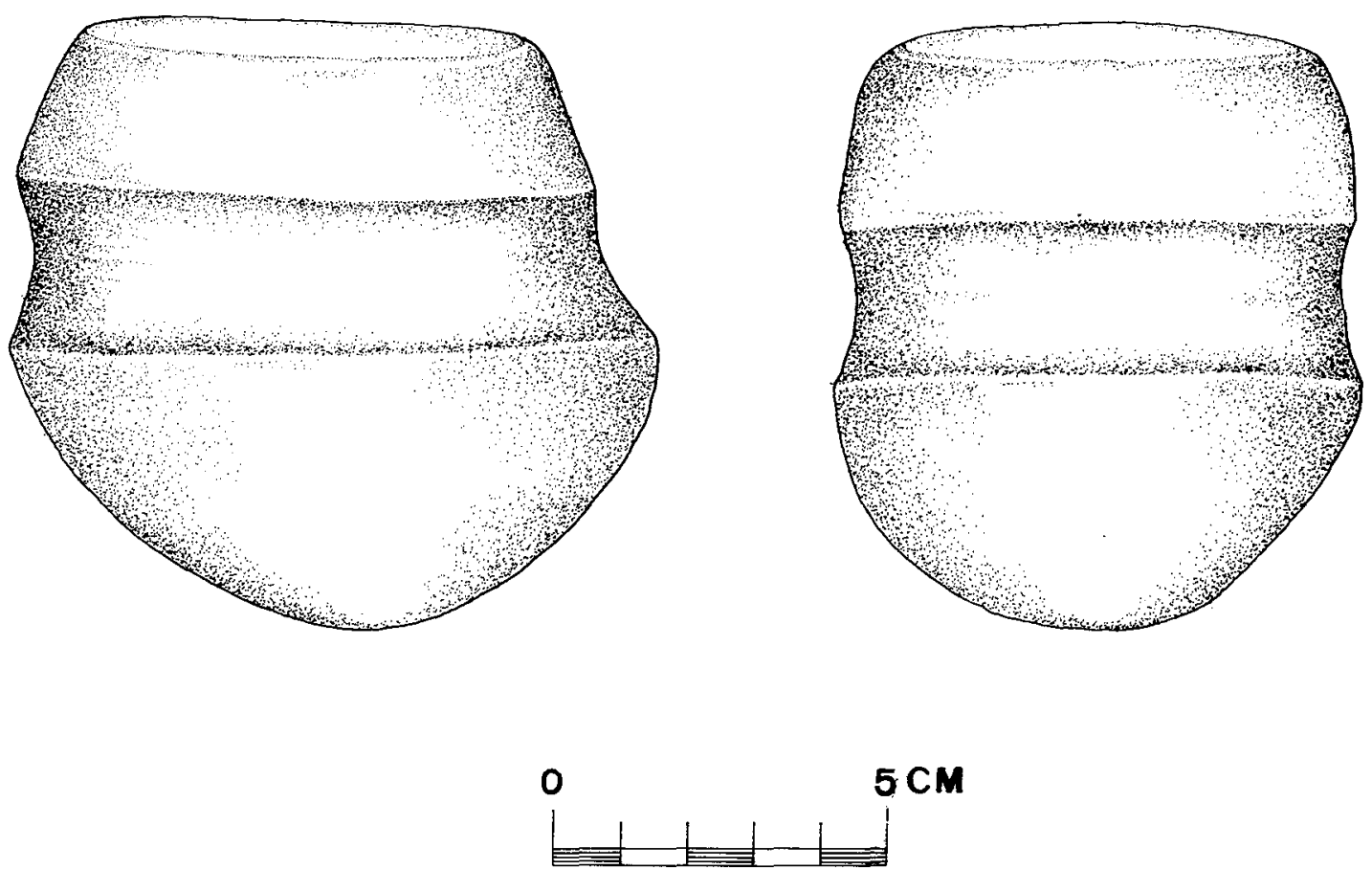

FIGURA 12

La información que podemos ofrecer por el momento se cierra con el análisis de los restos de fauna recuperados en la campaña de 1978. La determinación se debe a I. Sarrión y el resultado, referido al número total de restos por especie, es el siguiente:

Especies domésticas

Capra/Ovis

Ovis aries

Capra hircus

Bos taurus

Sus domesticus

Canis familiaris

Especies silvestres

Equus sp.

Cervus elaphus

Capreolus capreolus

Sus scropha

Oryctolagus cuniculus

Lepus capensis

Vulpes vulpes

Meles meles

TOTAL

Mauremus caspica

$\mathrm{Pez}$

Restos śeos indet.
$N . R$.

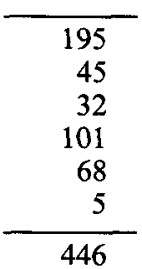

32

01

46

4,66
9,87

$\%$

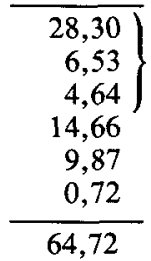

0,43

27,87

192

0,15

0,29

5,37

0,87

0,15

0,15

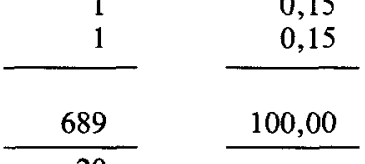

20

2.829 


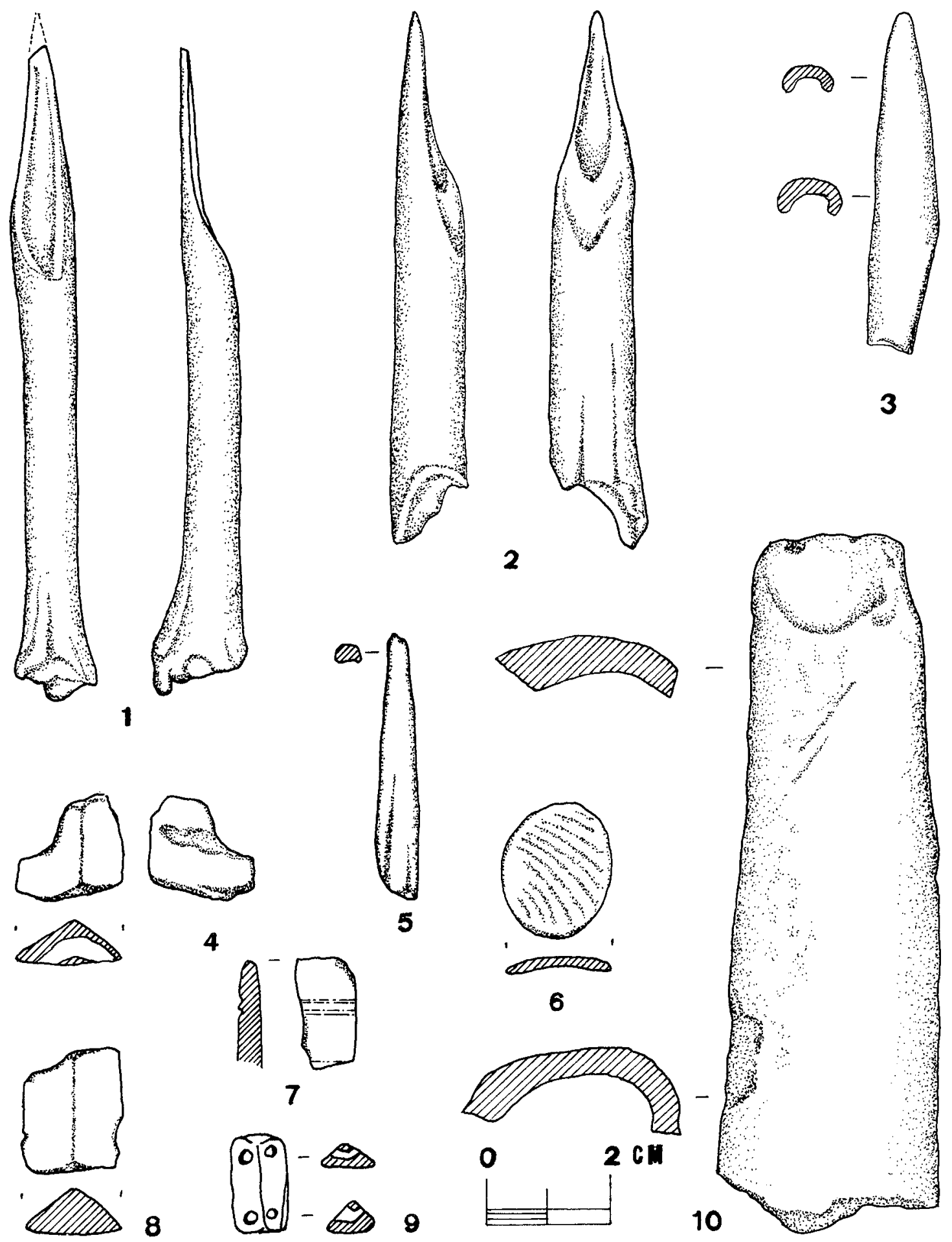

FIGURA 13 

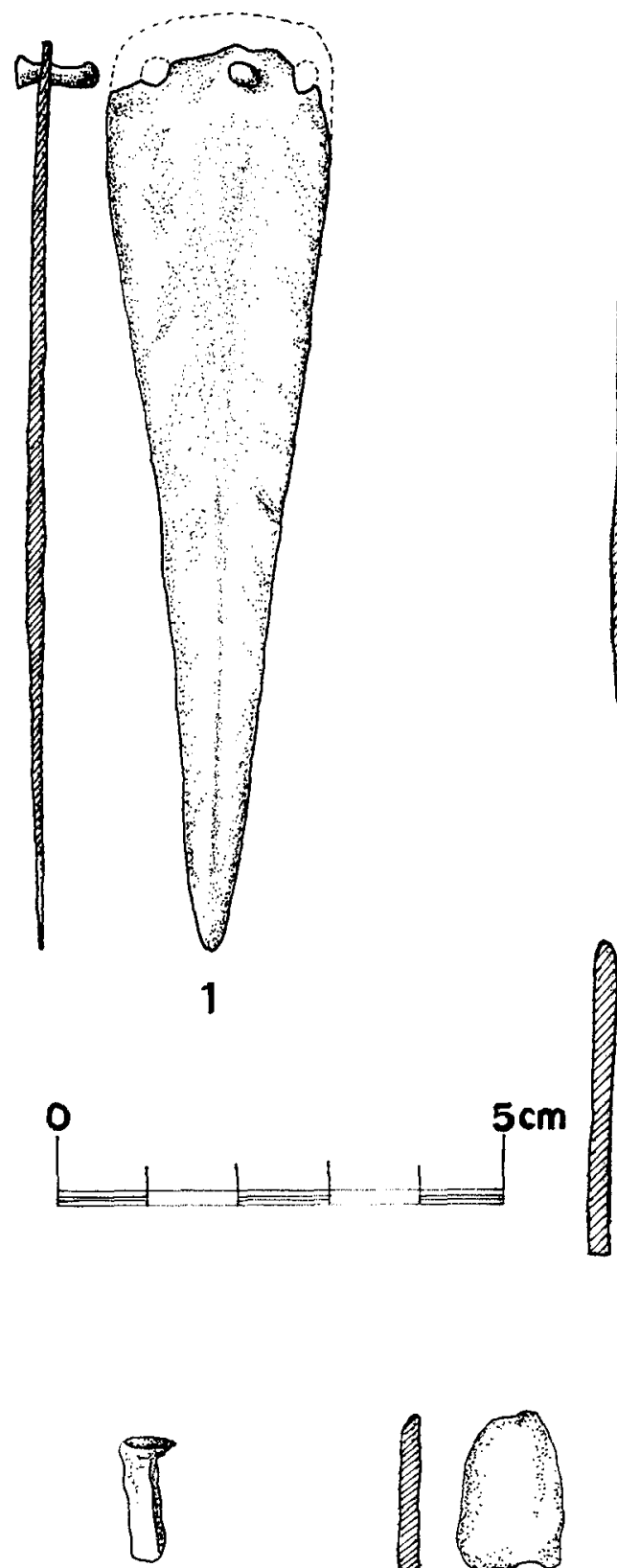

7

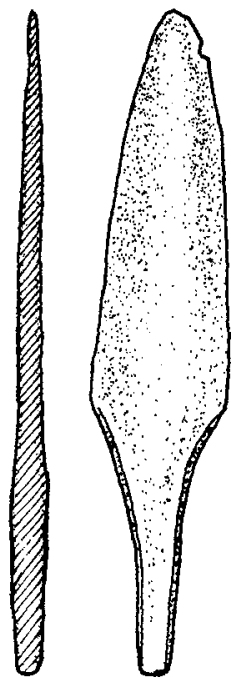

2
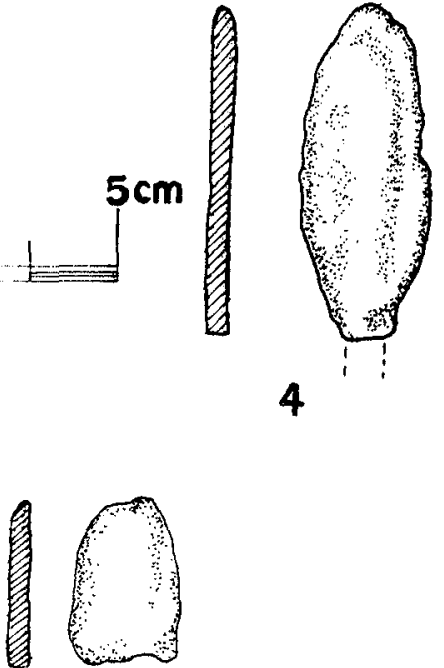

8

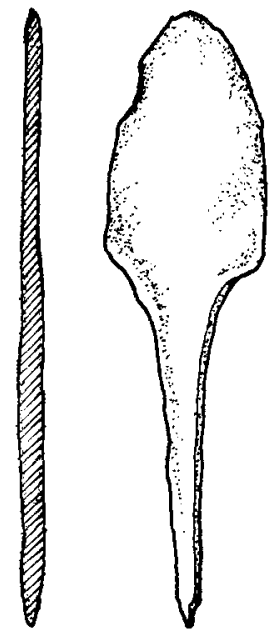

3

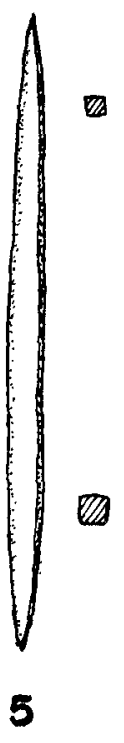

FIGURA 14

Estos resultados ponen de manifiesto que, si bien estamos ante una cultura agrícola y ganadera, existe también una asidua práctica cinegética.

Entre los animales domésticos, considerando los datos que poseemos desde el Neolítico, vemos un aumento considerable de los cápridos en relación a los óvidos, aunque éstos siguen siendo predominantes. Destaca igualmente el elevado número de los restos de bóvidos, entre los que predominan los animales viejos, indicio de que fueron objeto 
de una plena explotación no sólo como productores de carne y leche, sino también como animales de carga y, quizás, de tiro en las labores agrícolas.

La proporción alcanzada por los restos de ciervo es extraordinariamente alta y, si bien el estudio de las campañas posteriores podrá matizar o alterar estas cifras, hemos de pensar que la importancia del ciervo no sólo responde a la necesaria protección de los cultivos sino que su caza supondría un aporte proteínico considerable y deliberadamente buscado. Por otra parte ello testimonia obviamente que las manadas de ciervos eran abundantes en la zona durante el transcurso de la Edad del Bronce, lo que unido a la presencia de un resto de corzo o a los de galápago nos sugiere unas condiciones de medio ambiente que nada tienen que ver con la dramática aridez supuesta en algunas ocasiones (APARCICIO, 1976).

\section{Atribución cultural y cronológica}

Cuanto hemos expuesto hasta aquí habla de la pertenencia de la Muntanya Assolada a la Cultura del Bronce Valenciano. La estructura y ubicación del poblado, al igual que la mayor parte de los materiales encontrados, corresponden a lo mostrado por los yacimientos más representativos de la cultura. Sin embargo, el hecho de que el Bronce Valenciano esté bien definido en sus caracteristicas generales, pero escasamente articulado en lo que se refiere a una precisa tipología de materiales y fases de evolución, conlleva algunas limitaciones.

El examen de los materiales comprueba que la tipología cerámica de la Muntanya Assolada está ampliamente representada en los yacimientos del Bronce Valenciano, como puede verse para el caso de las formas presentes en el poblado de la Serra Grossa de Alacant (LLOBREGAT, 1969). Quizás la novedad más destacada la constituyen los vasos carenados, entre los que algunos se asemejan a los de la Muntanyeta de Cabrera de Torrent (FLETCHER y PLA, 1956), Mas de Menente en Alcoi (PERICOT y PONSELL, 1928) y Serra Grossa; mientras otros encuentran sus paralelos más próximos en el Torrelló de Onda (GUSI, 1974). Para los primeros, con carena media o alta y cuello más estrecho, D. Fletcher y E. Plá $(1956,37)$ señalaron su mayor antigüedad de acuerdo con su presencia en yacimientos considerados como anteriores al Argar. Por el contrario, los vasos con carena en el mitad inferior del vaso y amplia boca, bien representados en el Torrelló, deben corresponder a momentos avanzados del Bronce Valenciano de acuerdo con las dataciones absolutas de este yacimiento, $1350 \pm 90$ y $1315 \pm 90$ a. de C., y con su presencia en la Ereta de Castellar de Vilafranca (ARNAL, PRADES y FLETCHER, 1968), el Castellet de Montserrat (APARICIO, 1972), la Llometa del Tío Figuetes de Benaguasil, etc., como ha señalado M. Gil Mascarell (1981 a) a propósito de algunos materiales del Tossal de Sant Miquel de LLíria. Los resultados obtenidos en las Motillas de la Mancha corroborarían igualmente el carácter evolucionado de estos vasos de carena baja y amplia boca (NAJERA y MOLINA, 1977; NAJERA et alii, 1979; MOLINA et alii, 1979). Sucedería aquí tal vez algo semejante a lo expuesto para los vasos carenados de la cerámica sepulcral de la Cultura del Argar donde, según $\mathrm{H}$. Schubart $(1979,299)$, en la fase A son más frecuentes los vasos con carena aproximadamente a media altura, frente a los cuales en la fase B predominan los vasos con carena baja. $\mathrm{Y}$ así, en un yacimiento tan íntimamente relacionado con el Bronce Valenciano como el Castillo de Frías; de Albarracín (Teruel) (ATRIAN, 1974), encontramos vasos carenados de distintos tipos con una datación absoluta para su nivel III de $1520 \pm 100$ a. de C.

Las cazuelas hemiesféricas o en casquete esférico están bien representadas en los yacimientos eneolíticos, como en la Ereta del Pedregal de Navarrés o en el poblado de la Font de Maïques de Quatretonda, con abundantes silos excavados en el suelo. Desde entonces puede seguirse su presencia en la mayor parte de los poblados de la Edad del 
Bronce, como en el caso de los citados hasta aquí, si bien merece destacarse la existencia de algunas cazuelas con el borde saliente en yacimientos como la Ereta del Castellar o Les Planetes de Benassal (GONZALEZ, 1978), asociadas a vasos de carena baja y amplia boca.

Los vasos geminados se encuentran en el Castillo de Frías de Albarracín, Ereta del Castellar, La Atalayuela de Losa del Obispo (ALCACER, 1946; BALLESTER, 1949), Orpesa la Vella (GUSI y OLARIA, 1977), La Torreta de Llíria (BALLESTER et alii, 1954), La Cardosilla de Requena, Mola Alta de Serelles en Alcoi (BOTELLA, 1928), Cabezo Redondo de Villena (SOLER, 1952), además de un posible ejemplar con carena muy baja en la Llometa del Tío Figuetes. No parecen característicos de una fase determinada; por el contrario, la diversa tipología que ofrecen les asigna un amplio espectro cronológico. Los apéndices centrales de los vasos geminados de la Atalayuela, la Cardosilla y Orpesa la Vella guardan gran similitud con una de las piezas en forma de pequeña mano de mortero de la Muntanya Assolada (fig. $6, n .^{\circ} 2$ ), mientras la otra (fig. $6, n .^{\circ} 4$ ) parece tratarse más bien de un botón, semejante al que vemos en un vaso de la Peña de la Dueña en Teresa (ALCACER, 1946). En relación con estos dos últimos objetos destacaremos su similitud con una pieza del Cerro de la Virgen de Orce (Granada), clasificada allí como pintadera (SCHULE y PELLICER, 1966, fig. 46, 3).

Las decoraciones cerámicas abren una nueva perspectiva por cuanto sus paralelos son muy escasos en los yacimientos del Bronce Valenciano. Así, la decoración bruñida en la superficie exterior aparece aquí por vez primera, y tampoco puede decirse que sean abundantes los paralelos peninsulares con una cronología semejante a la de la Muntanya Assolada. Estos paralelos se reducirían a los yacimientos argáricos de Ifre (Murcia) (SIRET, 1890, lám. 18) y Fuente Alamo, en Cuevas de Almanzora (Almería) (ARTEAGA y SCHUBART, 1980, 267, fig. 11, c), si bien en éstos la decoración bruñida corresponde a la superficie interior de una copa y un vaso con pie, respectivamente. Por lo demás, las líneas bruñidas, como técnica decorativa, son abundantes en la mitad meridional de la Península Ibérica, sobre todo en el interior de cuencos y platos, y su cronología muy dilatada, desde momentos precampaniformes o de la Edad del Cobre en el valle del Guadalquivir a los casos antes citados de la Cultura del Argar y, sobre todo, del Bronce Final (FERNANDEZ y RUIZ, 1978).

El cuenco con decoración incisa en la superficie interior también carece de paralelos próximos. Por la técnica de cortas incisiones en las líneas oblicuas, recuerda al de la Muntanyeta de Cabrera (FLETCHER y PLA, 1956, lám. VI, c), pero sus mayores semejanzas se dirigen hacia los cuencos decorados en el interior y en el exterior del Cerro de la Virgen, estratos II A y II B, clasificados como campaniformes y considerados anteriores al Argar A (SCHULE y PELLICER, 1966, fig. 13, 1 y fig. 30, 1), pudiendo añadirse algunos otros paralelos peninsulares no demasiado estrechos, excepto el que se trate de decoraciones incisas en el interior. Entre estos últimos destacaremos los cuencos campaniformes incisos en la superficie exterior e interior del estrato A 3/B 2 del yacimiento de Hornos del Segura (Jaén), donde en el estrato inmediatamente superior, el A 2/B 1, considerado por J. Maluquer (1974) como argárico inicial, se encuentra una vasija de galbo muy acampanado decorada internamente mediante líneas incisas y pequeñas punzadas, motivo semejante al del fragmento carenado de la Muntanya Assolada. Decoraciones de líneas incisas y pequeños puntos impresos los encontramos también en algunos yacimientos argáricos como Fuente Alamo, el Oficio en Cuevas de Almanzora y Lugarico Viejo en Antas (Almería) (SIRET, 1890, láms. 16, 62 y 65).

Dentro del Bronce Valenciano, el motivo solar de la olla con decoración acanalada recuerda los fragmentos decorados del Castillarejo de los Moros de Andilla (FLETCHER y ALCACER, 1958), aunque en este caso parece tratarse más bien de una representación oculada. Algunos fragmentos incisos pueden contabilizarse dispersamente en 
otros yacimientos como el Castillo de Frías de Albarracín, el apéndice central del vaso geminado de la Atalayuela, Cova Foradada en Alcoi, etc. Mayor generalidad corresponde a los pequeños mamelones situados junto al labio, destacando la pequeña cazuela o cuenco del Castillarejo de los Moros. Y lo mismo puede decirse de los cordones lisos, digitados o ungulados, así como de las incisiones sobre el labio de los vasos.

La notable presencia de cerámicas decoradas en la Muntanya Assolada contrasta con su ausencia en la mayor parte de los restantes yacimientos, aun reconociendo que la importancia de las decoraciones es muy pequeña, si atendemos al total de los hallazgos cerámicos. A nuestro juicio, la explicación de tal particularidad estaría en relación con la presencia de otros materiales que, como el trapecio asimétrico, las puntas de flecha de sílex de retoque bifacial, los dos fragmentos de brazaletes de piedra y otros, apuntan hacia una tradición anterior; y en las semejanzas que pueden postularse para algunos de los motivos decorativos con respecto a los vasos campaniformes incisos, en especial con los de la Cova dels Gats de Alzira, necrópolis muy cercana a la Muntanya Assolada. De modo que resultaría factible admitir, como postula J. Bernabeu (1979), la existencia de una tradición todavía poco estudiada en la decoración de las primeras cerámicas del Bronce, posiblemente derivada de la técnica incisa campaniforme. Lo que tiene gran importancia a la hora de establecer la cronología inicial del Bronce Valenciano y su relación con el llamado Horizonte Campaniforme de Transición, dado que mientras se supone una notable perduración del llamado campaniforme inciso hasta bien entrado el segundo milenio, éste no aparece en los poblados del Bronce Valenciano que, sin embargo, se fechan inicialmente en torno al 1900/1800 a. de C.

Los restantes materiales confirman lo expuesto para la cerámica. En la industria lítica hemos destacado la singularidad del trapecio y, en menor medida, de las puntas de flecha de retoque bifacial. Aunque en pequeño número, puntas de flecha de sílex se conocen en otros yacimientos del Bronce Valenciano, como en la Ereta del Castellar, y también se han encontrado en las recientes excavaciones de la Mola de Agres (GILMASCARELL, 1981 b), lo que indica su larga pervivencia y, consecuentemente, difícil evaluación sin un contexto más preciso. En el caso de nuestro yacimiento destaca el ejemplar con base cóncava, tipo muy escaso en el País Valenciano (PLA, 1956).

Dientes de hoz de sílex, fragmentos de hoja, restos de talla, molinos de mano, azuelas, cuentas discoidales, brazaletes de arquero, etc., son elementos frecuentes en los poblados (PLA, 1964; ENGUIX, 1975). Los brazaletes de piedra aparecen por vez primera en un contexto del Bronce Valenciano y su valoración ya ha sido expuesta en relación con la tradición ornamental anterior. Con respecto a lo que se ha descrito como un fragmento de anillo de hueso, su singularidad se extiende también al Eneolítico y, por otra parte, no es segura su pertenencia a este tipo. Botones prismáticos triangulares con perforación en V se conocen en el poblado de las Peñicas de Villena (SOLER, 1952), y en el Cabeço del Navarro de Ontinyent (ENGUIX, 1970); ejemplares alargados con doble perforación se encuentran también en las Peñicas y en la Font de l'Almaguer de Alfarb (PITARCH, 1970); prismas triangulares sin perforación los encontramos en la Muntanyeta de Cabrera y en la Mola d'Agres. Los punzones biselados y los robustos cinceles de hueso, así como las esquirlas aguzadas, son materiales frecuentes, al igual que las conchas con el ápice perforado.

Los haliazgos metálicos poseen una tipología reducida: puñal de remaches, puntas de flecha y punzones. De ellos sólo los punzones aparecen en contextos eneolíticos y del Horizonte Campaniforme de Transición, mientras que los otros dos tipos son propios de la Edad del Bronce. Conjuntos similares se documentan en los poblados de Els Germanells de Rafelbunyol, Cabezo Redondo de Villena y en San Antón de Orihuela, siendo numerosos los hallazgos de uno u otro elemento (LERMA, 1981). Destacan los resultados de los análisis en curso, que indican la presencia de auténtico bronce en dos de 
las piezas mientras que. con anterioridad, sólo se había determinado la presencia de estaño de forma muy escasa en una lámina procedente de la Mola Alta de Serelles (BLANCE, 1959), por lo que no se trataba de verdadero bronce. En los últimos años también se ha determinado la presencia de bronce en los yacimientos de la Horna de Aspe y la Pedrera de Monforte (HERNANDEZ, 1983).

El avance del estudio sobre los restos de fauna merece una atención especial por cuanto, a la espera de los necesarios estudios sedimentológicos y polínicos en curso, los restos de fauna, en tanto que son representativos de la actividad económica de los grupos humanos y del medio ambiente del que proceden, no parecen indicar aquellas extremadas condiciones climáticas supuestas en ocasiones durante el transcurso del Bronce Valenciano (MARTI, 1983).

Así pues, los resultados alcanzados hasta ahora en la Muntanya Assolada la definen como un asentamiento característico del Bronce Valenciano y, a juzgar por los restoṡ constructivos exhumados y por la abundancia de los materiales recuperados, cabe esperar de su excavación y estudio una importante contribución al conocimiento de esta cultura.

Durante los últimos años la investigación ha ido poniendo de manifiesto que aquella imagen del Bronce Valenciano como una cultura fundamentalmente homogénea e invariable, acuñada en las primeras etapas de su estudio (TARRADELL, 1969), debía dejar paso a la consideración de posibles fases evolutivas (GUSI, 1975; ENGUIX, 1980) y de diferenciaciones geográficas internas (NAVARRO, 1982). Por lo que se refiere a sus momento iniciales, es obvio que la marcada y muy distinta personalidad del Bronce Valenciano con respecto al Eneolítico implicaba necesariamente una fase de transición, tradicionalmente aislada a partir de las necrópolis (MARTI, 1981) y que ahora empieza a dibujarse en los poblados, como ha podido ser estudiado en el caso de la Ereta del Pedregal de Navarrés (PLA et alii, 1982). Tales resultados condicionan la cronología que puede atribuirse a los comienzos de la Edad del Bronce en nuestras tierras y, a pesar de algunas fechas absolutas de mayor antigüedad, sugieren una datación inicial en torno al $1800 / 1700$ a. de C., cronología que podemos atribuir a la primera ocupación de la Muntanya Assolada, en la que hemos creído observar claros testimonios de la anterior tradición eneolítica.

También la determinación del final de la ocupación del yacimiento va íntimamente ligada a los problemas generales de la cultura. Aquí todo parece radicar, por el momento, en la consideración que pueda hacerse de los vasos con carena baja y amplia boca, propios del nivel superior. El carácter avanzado de tales vasos parece indudable de acuerdo con los paralelos conocidos, aunque éstos no han de considerarse siempre como satisfactorios, especialmente en los casos de muy acusada carena. M. Gil Mascarell (1981 c) ha expuesto recientemente los materiales y el estado de la cuestión sobre el período final del Bronce, mostrando la posibilidad de que en el País Valenciano se produjera una evolución semejante a la observada en el área del sudeste peninsular con las fases del Bronce Tardío y Bronce Final, que se desarrollarían con posterioridad al Bronce Pleno o Bronce Valenciano, pero aceptando también la posibilidad de perduraciones absolutas del Bronce Valenciano durante el transcurso de aquellas dos últimas fases. Tal planteamiento puede resumir los problemas que subyacen a la hora de valorar el límite final de la Muntanya Assolada que, por el conjunto de los materiales y por los paralelos expuestos, haríamos coincidir con el final del Bronce Pleno, con unas dataciones próximas a las del Torrelló de Onda, a la espera de que el más detenido estudio de la secuencia del poblado y las futuras campañas de excavación nos permitirán alcanzar mayores precisiones. 


\section{BIBLIOGRAFIA}

ALCACER, J. 1946: «Dos estaciones argáricas en la región levantina». Archivo de Prehistoria Levantina, $2,151-163$.

A. M. A.: Archivo Municipal de Alzira. Actas de sesiones del Ayuntamiento del 26 de noviembre de 1783, folio 103-104, y del 20 de diciembre de 1783, folio 14 .

APARICIO, J. 1972: «El poblado de la Edad del Bronce del Castellet (Montserrat, Valencia). Archivo de Prehistoria Levantina, 13, 23-50.

APARICIO, J. 1976: Estudio económico y social de la Edad del Bronce Valenciano, Valencia.

ARNAL, J.; PRADES, H. y FLETCHER, D. 1968: La Ereta del Castellar (Vilafranca del Cid, Castellón), Valencia.

ARTEAGA, O. y SCHUBART, H. 1980: «Fuente Alamo, Excavaciones de 1977». Noticiario Arqueológico Hispánico, 9, 245-289.

ATRIAN, P. 1974: «Un yacimiento de la Edad del Bronce en Frías de Albarracín». Teruel, 52, 7-32.

BALLESTER, I. 1949: «Excavaciones en la Atalayuela (Losa del Obispo)». La Labor del S. I. P. y su Museo en los años 1940-1948, Valencia, 101-113.

BALLESTER, I.; FLETCHER, D.; PLA, E.; JORDA, F. y ALCACER, J. 1954: Corpus Vasorum Hispanorum. Cerámica del Cerro de San Miguel. LLíria, Madrid.

BERNABEU, J. 1979: «Los elementos de adorno en el Eneolítico valenciano». Papeles del Laboratorio de Arqueologia de Valencia-Saguntum, 14, 109-126.

BLANCE, B. 1959: «Estudio espectrográfico de algunos objetos metálicos del Museo de Pehistoria de la Diputación de Valencia». Archivo de Prehistoria Levantina, 8, 163-173.

BOTELLA, E. 1928: «Excavaciones en la Mola Alta de Serelles (Alcoy)», Memorias de la Junta Superior de Excavaciones y Antigüedades, 94.

CAVANILLES, A. J. 1795: Observaciones sobre la Historia Natural, Geografía, Agricultura, Población y Frutos del Reyno de Valencia, Madrid.

ENGUIX, R. 1970: «Cabeço del Navarro o Cabeço dels Alforins de Onteniente. Poblado de la Cultura del Bronce Valenciano». Papeles del Laboratorio de Arqueología de Valencia, 10, 63-79.

ENGUIX, R. 1975: «Notas sobre economía del Bronce Valenciano». Papeles del Laboratorio de Arqueología de Valencia, 11, 141-157.

ENGUIX, R. 1980: "La Edad del Bronce». Nuestra Historia, I, Valencia, 151-170.

FERNANDEZ, F. y RUIZ, D. 1978: «El tholos del Cerro de la Cabeza, en Valencina de la Concepción (Sevilla)?. Trabajos de Prehistoria, 35, 193-224.

FLETCHER, D. y ALCACER, J. 1958: «El Castillarejo de los Moros (Andilla, Valencia)». Archivo de Prehistoria Levantina, 7, 93-110.

FLETCHER, D. y PLA, E. 1956: El poblado de la Edad del Bronce de la Montanyeta de Cabrera (Vedat de Torrente). Valencia.

GIL-MASCARELL, M. 1981 a: «Algunos materiales prehistóricos del Cerro de Sant Miquel de Llíria». Archivo de Prehistoria Levantina, 16, 361-371.

GIL-MASCARELL, M. 1981 b: «El poblado de la Mola d'Agres. Dos cortes estratigráficos». Papeles del Laboratorio de Arqueología de Valencia-Saguntum, 16, 75-89.

GIL-MASCARELL, M. 1981 c: «Bronce tardío y Bronce final en el País Valenciano». El Bronce Final y el comienzo de la Edad del Hierro en el País Valenciano, Valencia, 9-39.

GONZALEZ, A. 1978: «Excavaciones en el poblado de la Edad del Bronce de Les Planetes, Mas d'en Serrans, Benassal (Castellón)». Cuadernos de Prehistoria y Arqueología Castellonense, 5, 206-241.

GUAL, M. 1953: «Hace tres mil años». Murta, Revista del Instituto Laboral de Alcira, octubre-diciembre, 4-5.

GUSI, F. 1974: «Excavaciones del recinto fortificado del Torrelló, de Onda (Castellón)». Cuadernos de Prehistoria y Arqueología Castellonense, 1, 19-62.

GUSI, F. 1975: «Las dataciones de C. 14 de la Cueva del Mas d’Abad (Coves de Vinromà). Campaña de 1975. Ensayo cronológico para la periodización del Bronce Valenciano». Cuadernos de Prehistoria y Arqueología Castellonense, 2, 75-79.

GUSI, F. y OLARIA, C. 1977: «El poblado de la Edad del Bronce de Orpesa la Vella (Orpesa del Mar, Castellón)». Cuadernos de Prehistoria y Arqueología Castellonense, 4, 79-100.

HERNANDEZ, M. S. 1983: «La metalurgia prehistórica en el Valle Medio del río Vinalopó (Alicante)». Lucentum, 3.

LERMA, J. V. 1981: «Los orígenes de la metalurgia en el País Valenciano». Archivo de Prehistoria Levantina, 16, 129-140.

LOPEZ, A. 1966: «Región Valenciana». Geografía de España y Portugal, IV, 2. ${ }^{a}$ parte, Barcelona. 
LLOBREGAT, E. 1969: «El poblado de la Cultura del Bronce Valenciano de la Serra Grossa, Alicante». Papeles del Laboratorio de Arqueología de Valencia, 6, 31-70.

MALUQUER, J. 1974: «La estratigrafía prehistórica de Hornos de Segura (Jaén)». Pyrenae, 10, 43-66.

MARTI, B. 1981: «La Cova Santa (Vallada, Valencia)». Archivo de Prehistoria Levantina, 16, 159-196.

MARTI, B. 1983: El nacimiento de la agricultura en el País Valenciano. Del Neolítico a la Edad del Bronce. Valencia.

MOLINA, F; NAJERA, T. y AGUAYO, P. 1979: «La Motilla del Azuer (Daimiel, Ciudad Real). Campaña de 1979)》. Cuadernos de Prehistoria de la Universidad de Granada, 4, 265-293.

NAJERA, T. y MOLINA, F. 1977: «La Edad del Bronce en la Mancha. Excavaciones en la Motilla del Azuer y los Palacios (Campaña de 1974)». Cuadernos de Prehistoria de la Universidad de Granada, 2, 251-300.

NAJERA, T.; MOLINA, F.; TORRE, F. de la; AGUAYO, P. y SAEZ, L. 1979: «La Motilla del Azuer (Daimiel, Ciudad Real). Campaña de 1976». Noticiario Arqueológico Hispánico, 6, 19-50.

NAVARRO, J. F. 1982: «Materiales para el estudio de la Edad del Bronce en el Valle medio del Vinalopó (Alicante)». Lucentum, 1, 19-70.

PELUFO, V. 1935: «Inundaciones, terremotos, pestes y otras calamidades que ha sufrido Alcira». Xúcar, 2, s. p.

PERICOT, L. y PONSELL, F. 1928: «El poblado del Mas de Menente (Alcoy)». Archivo de Prehistoria Levantina, 1, 101-102.

PITARCH, J. L. 1970: «Un botón prismático alargado de la Font de l'Almaguer». Papeles del Laboratorio de Arqueología de Valencia, 10, 81-90.

PLA, E. 1956: «Puntas de base cóncava en la Región Valenciana». IV Congreso Internacional.de Ciencias Prehistóricas y Protohistóricas (Madrid, 1954), Zaragoza, 459.

PLA, E. 1964: «Los llamados brazaletes de arquero y el Eneolítico valenciano». VIII Congreso Nacional de Arqueología (Sevilla-Málaga 1963), Zaragoza, 216-225.

PLA, E.; MARTI, B. y BERNABEU, J. 1982: «La Ereta del Pedregal (Navarrés, Valencia) y los inicios de la Edad del Bronce». Comunicación al XVI Congreso Nacional de Arqueología, Murcia.

SAN PEDRO, B. de, 1784: Descripción del hundimiento y cortaduras del Monte del Baladre, territorio de Alcira. Valencia.

SCHUBART, H. 1979: «Nuevas fuentes para la Cultura del Argar». XV Congreso Nacional de Arqueología (Lugo, 1977), Zaragoza, 297-308.

SCHULE, W. y PELLICER, M. 1966: El Cerro de la Virgen. Orce (Granada). Madrid.

SIRET, E. y L. 1890: Las primeras edades del metal en el sudeste de España. Barcelona.

SOLER, J. M. 1952: «Villena (Alicante). Poblado del Cabezo Redondo». Noticiario Arqueológico Hispánico, $1,38-43$.

SOLER, J. M. 1952: «Villena (Alicante). Poblado de las Peñicas». Noticiario Arqueológico Hispánico, $1,44$.

TARRADELL, M. 1969: «La Cultura del Bronce Valenciano. Nuevo ensayo de aproximación». Papeles del Laboratorio de Arqueología de Valencia, 6, 7-30. 